\title{
Laboratory measurements and multi-block numerical simulations of the mean flow and turbulence in the non-aerated skimming flow region of steep stepped spillways
}

\author{
Fabián A. Bombardelli · Inês Meireles • Jorge Matos
}

Received: 29 December 2009 / Accepted: 1 August 2010 / Published online: 26 August 2010

(C) The Author(s) 2010. This article is published with open access at Springerlink.com

\begin{abstract}
We present and discuss the results of a comprehensive study addressing the non-aerated region of the skimming flow in steep stepped spillways. Although flows in stepped spillways are usually characterized by high air concentrations concomitant with high rates of energy dissipation, the non-aerated region becomes important in small dams and/or spillways with high specific discharges. A relatively large physical model of such spillway was used to acquire data on flow velocities and water levels and, then, well-resolved numerical simulations were performed with a commercial code to reproduce those experimental conditions. The numerical runs benefited from the ability of using multi-block grids in a Cartesian coordinate system, from capturing the free surface with the TruVOF method embedded in the code, and from the use of two turbulence models: the $k-\varepsilon$ and the RNG $k-\varepsilon$ models. Numerical results are in good agreement with the experimental data corresponding to three volumetric flow rates in terms of the time-averaged velocities measured at diverse steps in the spillway, and they are in very satisfactory agreement for water levels along the spillway. In addition, the numerical results provide information on the turbulence statistics of the flow. This work also discusses important aspects of the flow, such as the values of the exponents of the power-law velocity profiles, and the characteristics of the development of the boundary layer in the spillway.
\end{abstract}

F. A. Bombardelli $(\varangle) \cdot$ I. Meireles

Department of Civil and Environmental Engineering, University of California,

Davis, 2001 Ghausi Hall, One Shields Ave., Davis, CA 95616, USA

e-mail: fabianbombardelli2@gmail.com; fabombardelli@ucdavis.edu; bmbrdll@yahoo.com

I. Meireles

Department of Civil Engineering, University of Aveiro, Campus Universitario de Santiago, 3810-193 Aveiro, Portugal

J. Matos

Department of Civil Engineering and Architecture, IST, Technical University of Lisbon,

Av. Rovisco Pais, 1049-001 Lisbon, Portugal 
Keywords Stepped spillway · Non-aerated flow · Multi-phase flows · Two-phase flows · Experimental data $\cdot$ Back-flushing Pitot tube $\cdot$ Conductivity probe $\cdot$ Numerical simulations . Computational fluid dynamics (CFD) . Turbulence modeling $\cdot k-\varepsilon$ model .

RNG $k-\varepsilon$ model

\section{Introduction}

The main hydraulic advantage of stepped spillways is the ability to dissipate more energy than smooth, conventional spillways. Although this is a strong reason to use stepped spillways, it was not until the improvement of roller compacted concrete (RCC) technology by the end of the twentieth century that the interest in stepped spillways was definitively renewed $[3,27]$. Currently, there is a considerable interest in evaluating the performance of stepped spillways over RCC dams for high specific discharges, in either the design of new spillways, or the re-analysis of existing spillways due to an update in the probable maximum flood.

In general terms, for moderate unit discharges, large quantities of air entrain upstream of the spillway toe after the boundary layer reaches the water depth. For higher specific discharges, the boundary layer can not reach the free surface at relatively short distances, and the non-aerated region dominates large portions of the flow in the spillway.

In the last two decades, extensive experimental research has been developed to characterize the flow on conventional stepped spillways for chute slopes typical of either embankment or concrete dams downstream of the inception point of air entrainment, including the assessment of variables such as air concentration and velocity distribution $[4,9,24,26,37,42,57,63,67$, $71]$ or the pressure field on the steps $[2,4,41,74,85]$. Empirical models have been developed for predicting the main air-water flow properties along the chute by Hager and Boes [45], Matos [57], Chanson [25], Boes and Hager [9,10], Meireles [65], Renna [71] and Ohtsu et al. [67]. In spite of this considerable number of studies, and to the best of our knowledge, only Amador [2], Amador et al. [3], Meireles et al. [65], Gonzalez and Chanson [43], Carvalho and Amador [23] and Meireles and Matos [64] have focused on the flow properties of the non-aerated flow region of stepped spillways.

In addition to studies in physical models, recent advances in computational codes and hardware technology allow for new opportunities to employ numerical solutions as a supplement to the available experimental tools for the analysis of flow in stepped spillways, and for helping in the design of such structures. In fact, numerical flow models can be used to optimize the layout of hydraulic structures to a certain degree, and then physical models can be used to study the three-dimensional (3D) details of the flow, as shown for instance by Bombardelli et al. [15] and Caisley et al. [22]. Further improvement of theoretical and numerical models will contribute strongly to the design of hydraulic structures, especially when combined with detailed turbulence models such as Large Eddy Simulations (LES), and with more reliable models for two-phase flows (see Bombardelli [11], as an example).

The number of studies on computational fluid dynamics (CFD) focusing on hydraulic structures has increased notably in the last 10 years [8, 15, 28, 35, 46, 50, 54, 68, 75-77, 80,87]. A small number of simulations of the skimming flow over stepped spillways have been communicated very recently [5,23,29-31,79], describing both the aerated and non-aerated flow regions. A detailed analysis of the above contributions for stepped spillways is presented in Table 1, revealing the following features/issues:

(i) The comparisons between numerical and experimental results in those papers have been mostly of qualitative nature; 


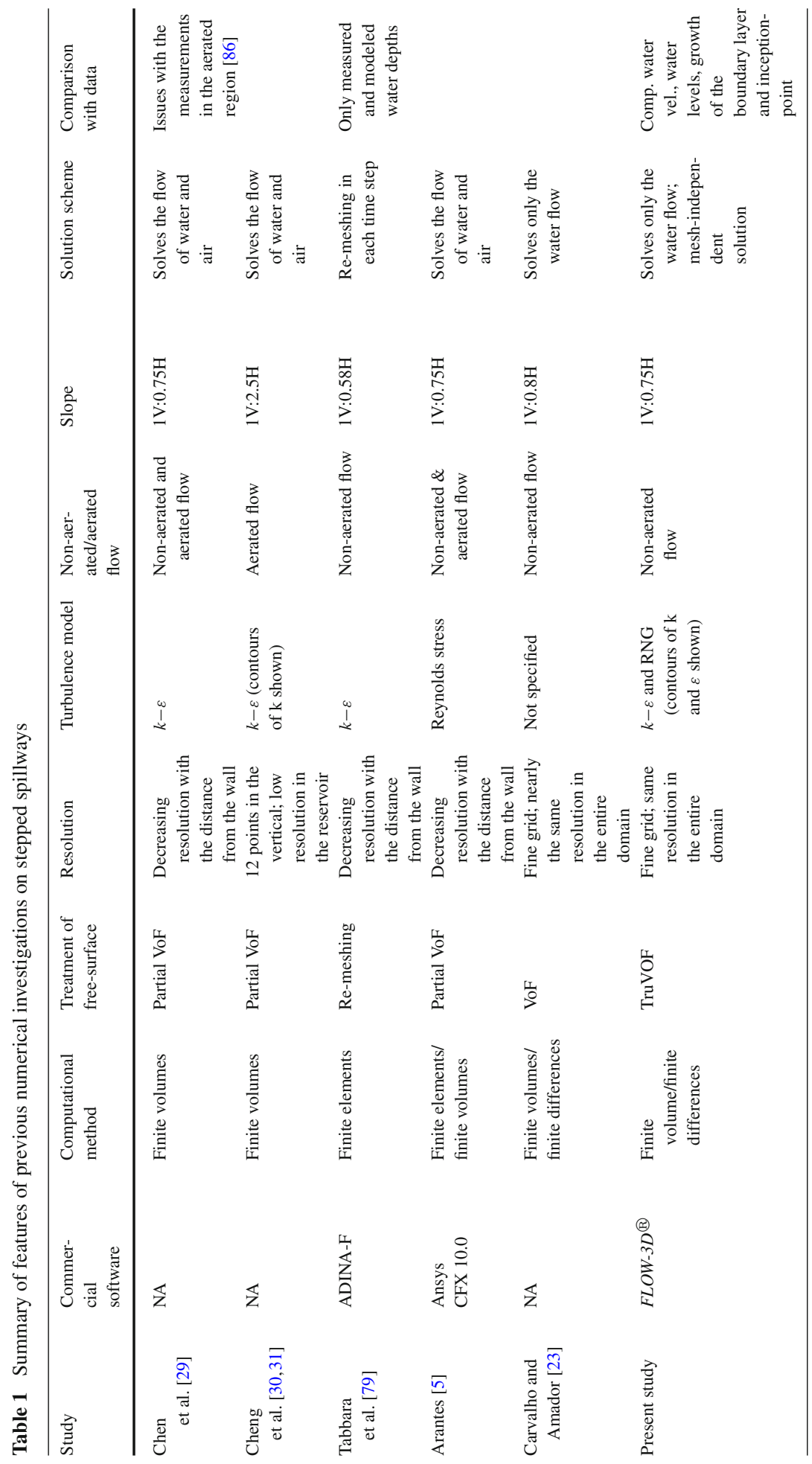


(ii) whereas Chen et al. [29] (see also Yasuda et al. [86]), Cheng et al. [30,31] and Arantes [5] solved the flows of water and air altogether (which was defined as Partial Volume-of-Fluid (VoF) method in Bombardelli et al. [16]), Tabbara et al. [79] employed a numerical strategy based on re-meshing each time step. In turn, Carvalho and Amador [23] used a purported VoF method, but they did not report comparisons of numerical results with data of the location of the free surface;

(iii) some of the simulations have been developed using unstructured grids with good resolution near the walls but with a lower resolution near the free surface;

(iv) only the papers by Cheng et al. [30,31] and Carvalho and Amador [23] include discussions on the distribution of turbulence statistics in the steps through contours of the turbulent kinetic energy (TKE) obtained numerically;

(v) experimental data obtained in some papers to validate the numerical simulations corresponded to relatively small facilities with potential significant scale effects;

(vi) to the best of our knowledge, very few numerical analyses of the non-aerated flow region which present and discuss comprehensive comparisons of computational results with data have been published in reputed peer-reviewed literature. Thus, more work is needed to understand completely the flow.

This paper therefore addresses the mean flow and turbulence statistics in the non-aerated flow region of steep stepped spillways. We have undertaken extensive experimental tests in a relatively large scale model at the National Laboratory of Civil Engineering (LNEC), in Lisbon, Portugal, and performed well-resolved simulations with the commercial, CFD code $F L O W-3 D^{\circledR}$ at the University of California, Davis, and Portugal. In addition to test the prediction capability of the commercial code through comparisons with our own experiments (an important task in its own right), we focus on investigating the following scientific issues with both experimental and numerical techniques:

(a) What is the evolution of the flow depth in the stepped spillway?

(b) What is the evolution of the boundary layer in the stepped spillway?

(c) What are the exponents of the power law representing the velocity profiles?

The paper is organized as follows. In Section 2, we present the experimental set-up. Sections 3 and 4 discuss the theoretical and numerical models employed. Section 5 presents comparisons of experimental and numerical results, focusing on the scientific questions stated above. Section 6 discusses the sensitivity analysis of the numerical solutions, followed by the conclusions.

\section{Experimental set-up}

The relatively large experimental model comprises a stepped chute, a stilling basin, and a recirculation system. The crest shape of the chute fits the U.S. Army Corps of Engineers, Waterways Experimental Station (WES) standard spillway profile, having a few steps with variable height to follow the profile (Fig. 1). The height of the spillway chute is $2.9 \mathrm{~m}$ (from crest to toe); the width is $1 \mathrm{~m}$; and the slope is $1 \mathrm{~V}: 0.75 \mathrm{H}\left(53^{\circ}\right.$ from horizontal; Fig. 2$)$. The stilling basin has a length of $5 \mathrm{~m}$ and the same width of the spillway. The basin finishes with a sluice gate which promotes the formation of a hydraulic jump.

Although this paper discusses only the non-aerated region of the flow, air concentrations and water velocities were measured in several step edges of the spillway with a conductivity probe and a back-flushing Pitot tube developed and calibrated by the U.S. Bureau of Reclamation $[57,58]$ (see Fig. 2). The air concentration data were used to estimate the equivalent clear 


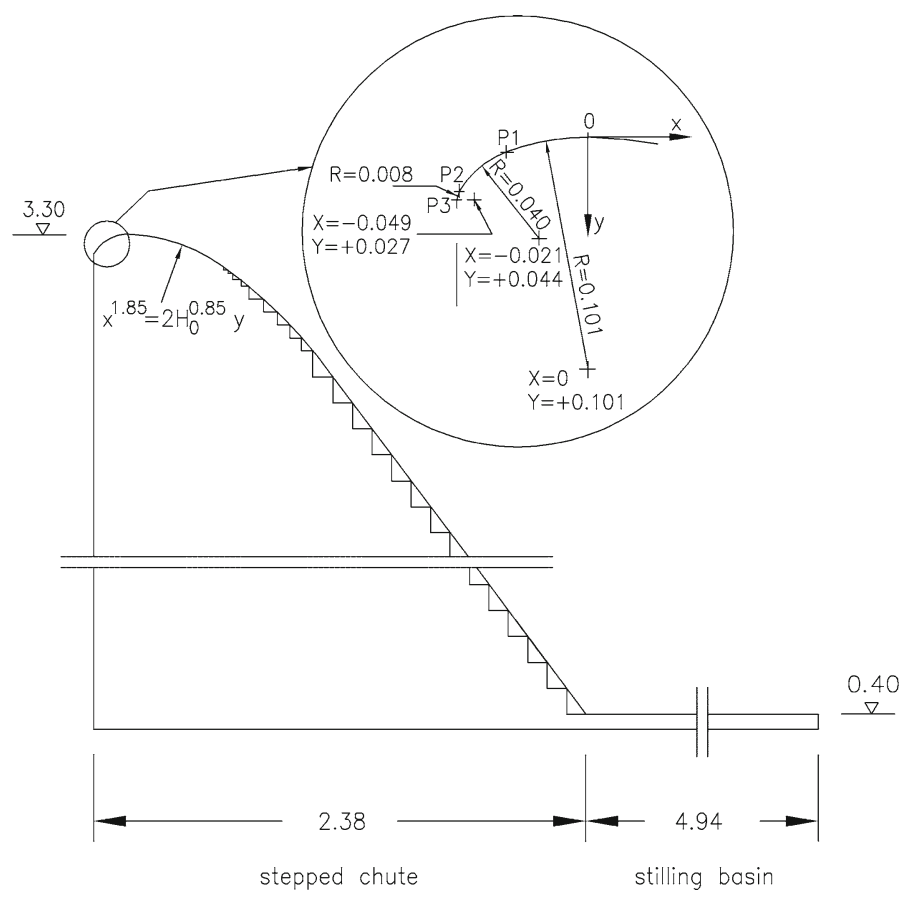

Fig. 1 Schematic diagram of the spillway (dimensions in meters)
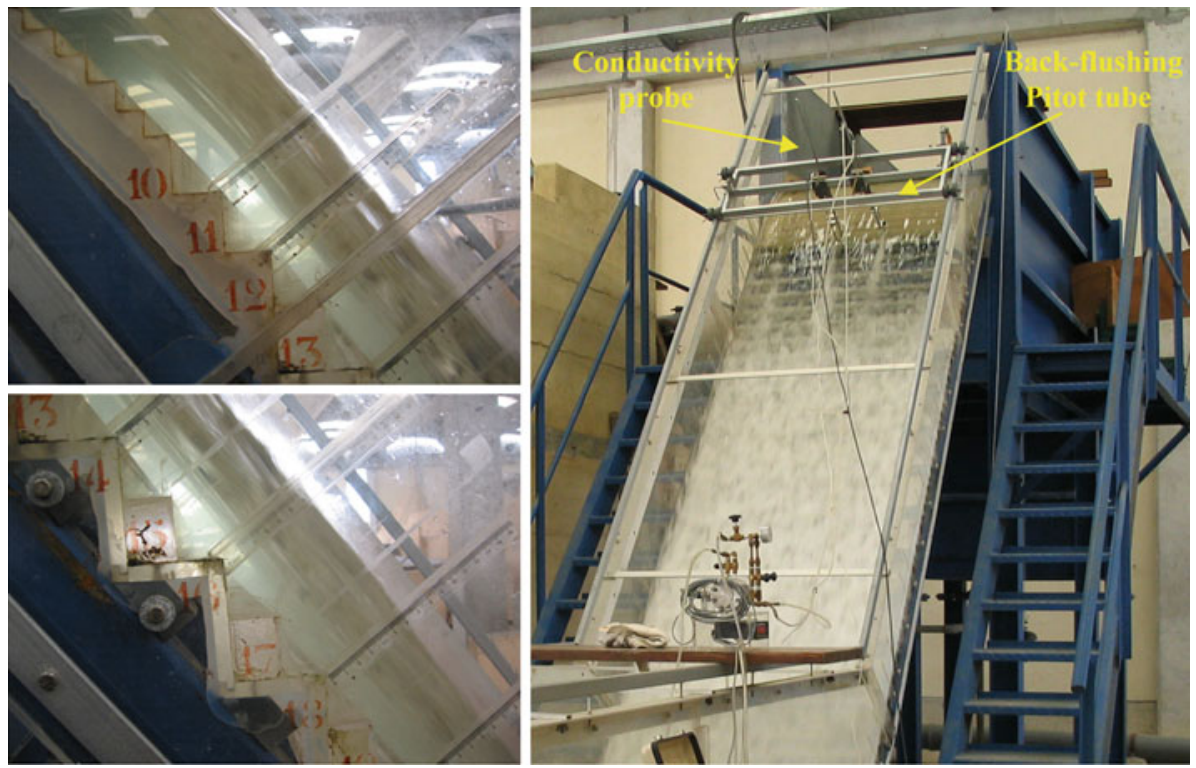

Fig. 2 Experimental flume and instrumentation (conductivity probe and back-flushing Pitot tube) at LNEC 
water depth, as well as to correct the differential pressure head data in the wavy region, so as to obtain the local time averaged velocity. The conductivity probe has two platinum wires with a diameter of $0.2 \mathrm{~mm}$. With the back-flushing Pitot tube, the total and static-pressure heads were measured through 1 - and 0.5 - mm diameter holes, respectively. Continuous backflushing of the Pitot tube was provided to avoid the entrance of air in the Pitot tube. Water was supplied from a reservoir with constant head which fed both the static-pressure and the total head ports of the Pitot tube. The back-flushing flow rate to each port was controlled by needle valves. A practically zero back-flushing flow rate was adopted in all tests. The output signal of the instrument was scanned at $30 \mathrm{kHz}$ for $90 \mathrm{~s}$ with a posteriori filtering to $30 \mathrm{~Hz}$ to save memory and storage. Further details can be found in Matos and Frizell [58].

The instruments were mounted on a trolley equipped with Vernier scales, and the accuracy for vertical distance measurements was of $\pm 0.1 \mathrm{~mm}$. The error for longitudinal distance measurements was estimated to be less than $5 \mathrm{~mm}$. In the transverse direction, the error was estimated to be less than $1 \mathrm{~mm}$.

We measured water depths with the help of point gauges at the chute centerline; we also undertook visual observations of the water depth at the sidewalls assisted by rulers installed in the flume. The volume flow rate (discharge) was measured with a Bazin weir located at the downstream end of the stilling basin, with value differences smaller than $8.8 \%$ (average of $5.5 \%$ ) when compared with velocity checks. Experimental tests were carried out for a step height $(h)$ of $4 \mathrm{~cm}$ and unit discharges $\left(q_{w}\right)$ ranging from 0.08 to $0.18 \mathrm{~m}^{2} / \mathrm{s}$, corresponding to the skimming flow regime [26].

Time-averaged velocities $(V)$ were obtained through:

$$
V=\sqrt{\frac{2 \Delta P}{\rho_{w}(1-C)}}
$$

where $\Delta P$ is the difference between the total pressure head and the static pressure head, measured with the back-flushing Pitot tube; $\rho_{w}$ is the density of water; and $C$ is the local air concentration. In the non-aerated region, $C$ refers to the air entrapped in the contorted free surface. (Near the inception point, $C$ can also denote the presence of air bubbles inside the flow, due to the difference between instantaneous and averaged inception point locations.) In fact, because of the waviness and turbulent nature of the flow, measurement points close to the free surface suffered from instances in which the instrumentation remained uncovered by water. The values of velocity close to the free surface correspond, therefore, to an average of moments of complete submergence and moments of uncovered condition of the backflushing Pitot tube and the conductivity probe. Even though Eq. 1 takes into account this phenomenon, these values of velocity should be taken with caution due to the high frequency of the free-surface waves as opposed to the time response of the Pitot tube [60]. For this reason, local velocity data where air concentration is different from zero have been indicated with unfilled symbols whereas filled symbols refer to data where air concentration is equal to zero (see Figs. 4, 5, 7, 9, 14 and 15).

Observations undertaken with tracers, along with the conductivity probe and the backflushing Pitot tube located in different verticals for each cross section, revealed an essentially two-dimensional (2D) flow above the step cavities, as expected. This is consistent with the relatively large width of the channel [32]. However, visualization of the flow within the step cavities showed that it was markedly 3D [26,43,44,59]. Notwithstanding this clear fact, we decided to undertake a $2 \mathrm{D}$ simulation of the entire flow, in agreement with most previous numerical works (see Table 1). 


\section{Mathematical model}

\subsection{General flow and transport model}

Our theoretical models are based upon the mixture equations for an air-water flow. We follow Buscaglia et al. [20], Bombardelli [15,16], Bombardelli et al. [14], and Bombardelli and Jha [12] in employing equations for a dilute mixture. The equations can be obtained via two consecutive averaging procedures [34,70]: (a) an ensemble averaging, which basically addresses the bubble-to-bubble distance, and (b) a turbulence averaging, which addresses turbulence scales larger than the inter-bubble distance [12]. Length scales of turbulence range from the Kolmogorov length scale to the largest scales of the flow (dictated by the flow depth or width; see Gioia and Bombardelli [40]). We believe that the length and time scales associated with the ensemble average are smaller than the intermediate to large scales pertaining to turbulence $[12,17,14,20]$. Consequently, we believe that the ensemble average represents only scales of the order of the bubble-to-bubble distance. Other authors have interpreted the ensemble average assuming that it considers all length scales [36]. Based on our hypothesis, we understand that an additional turbulence (time) average of the equations is necessary, to account for the intermediate and large scales of turbulence (see also Hrenya and Sinclair [51] and discussion in Chap. 8 of Prosperetti and Tryggvason [70] on the nature of the averaging procedures). The models have naturally the single-phase flow as a special case.

Although our main interest is the flow in the non-aerated region of the spillway, we needed to solve the two-phase flow equations to represent as accurately as possible the flow in the aerated region and in the stilling basin (see below). The mixture equations for a 3D dilute flow are as follows:

$$
\begin{gathered}
\nabla \cdot \overline{\underline{u}_{m}}=0 \\
\frac{\partial\left(\rho_{0} \underline{\underline{u}_{m}}\right)}{\partial t}+\nabla \cdot\left(\rho_{0} \underline{\underline{u}}_{m} \otimes \underline{u}_{m}\right)=\underline{B}-\nabla \bar{p}+\mu \nabla \cdot\left(\nabla \overline{\underline{u}_{m}}+\nabla \underline{\underline{u}}_{m}^{T}\right)-\nabla \cdot\left(\rho_{0} \overline{\underline{u}}_{m}^{\prime} \otimes \underline{u}_{m}^{\prime}\right)
\end{gathered}
$$

where $\bar{u}_{m}$ refers to the time-averaged mixture velocity vector; $\rho_{0}$ indicates the reference density; $\underline{B}$ is the vector of body forces; $\bar{p}$ denotes the time-averaged, modified pressure [20,72]; $\mu$ refers to the dynamic viscosity; $t$ is the time coordinate; and $\underline{u}_{m}^{\prime}$ indicates the fluctuating mixture velocity vector. In turn, $\otimes$ refers to the tensor product; $T$ denotes the transpose of a tensor; and the underline indicates vectors. For this problem, the only acting body forces are those from the gravitational field. In order to account for turbulence, the Boussinesq model considers the Reynolds stresses to be proportional to the gradient of mean velocity, as follows [72]:

$$
\begin{aligned}
-\rho_{0} \overline{\underline{u}_{m}^{\prime} \otimes \underline{u}_{m}^{\prime}} & =\mu_{T}\left(\nabla \underline{\bar{u}}_{m}+\nabla \underline{\bar{u}}_{m}^{T}\right)-\frac{2}{3} \rho_{0} k \underline{\underline{I}} \\
\mu_{T} & =\rho_{0} C_{\mu} \frac{k^{2}}{\varepsilon}
\end{aligned}
$$

where $\mu_{T}$ is the eddy dynamic viscosity; and $C_{\mu}$ is a coefficient of the order of 0.09 . $k$ denotes in turn the turbulent kinetic energy (TKE), defined in this context as: $k=\frac{1}{2} \underline{\underline{u}}_{m}^{\prime} \cdot \overline{u_{m}^{\prime}}$; $\varepsilon$ is the dissipation rate of TKE; and $\underline{I}$ denotes the identity tensor. The standard $k-\varepsilon$ turbulence model [55], and the RNG $k-\varepsilon$ model $[83,84]$ were used in this work. The RNG $k-\varepsilon$ model is usually considered to provide more accurate results than the $k-\varepsilon$ model in flows 


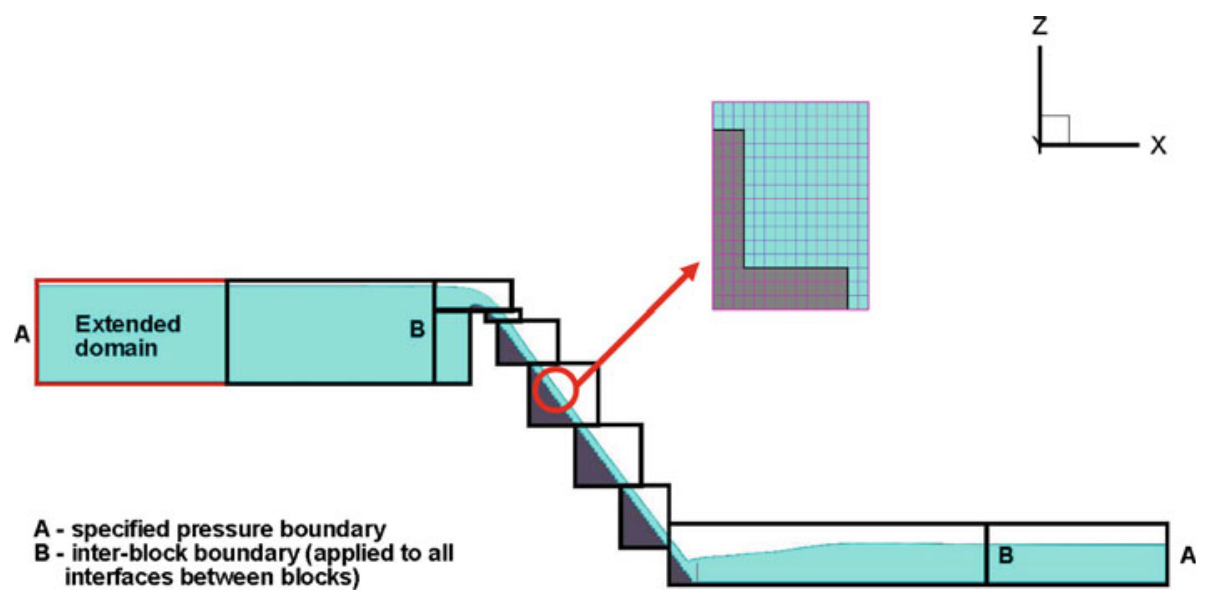

(a)
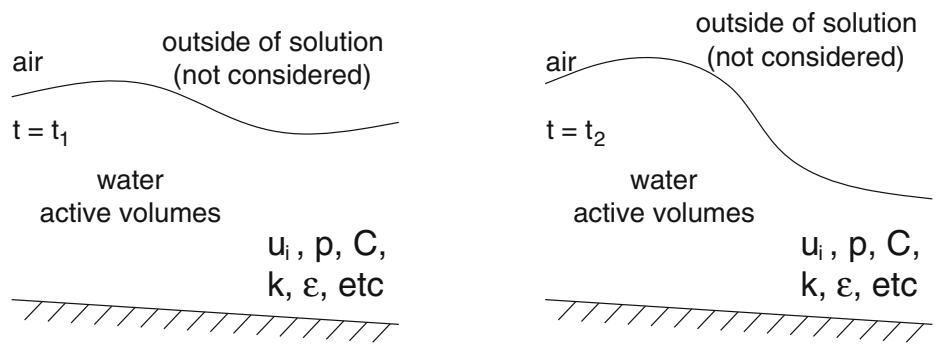

(b)

Fig. 3 a Model geometry and distribution of blocks in the multi-block grid. The figure includes the "short" and "extended" computational domains. Rectangles denote the blocks of the multi-block gridding operation. Notice the savings in computational effort produced by the location of the blocks. $\mathbf{b}$ Schematic showing that transport equations are solved in the liquid only in FLOW-3D(R) [38, p. 384]

with low turbulence intensity and, very importantly, in flows with important shear regions, such as the flow under study in this paper [39].

The theoretical model also incorporates a transport equation for the air which is entrained at the free surface as follows:

$$
\frac{\partial C}{\partial t}+\nabla \cdot\left[\left(\underline{\underline{u}}_{m}+\underline{W}_{s}\right) C\right]=\nabla \cdot(\underline{\underline{D}} \cdot \nabla C)
$$

where $C$ is the volumetric concentration of air; $\underline{W}_{S}$ is the slip-velocity vector (which points in the positive vertical direction); and $\underline{D}$ denotes the air-diffusivity tensor.

This equation is solved in the water volumes, as detailed in next section and Fig. $3 \mathrm{~b}$. According to the hierarchical framework of possible two-phase models developed by Bombardelli [12], Bombardelli et al. [17] and Bombardelli and Jha [14], this corresponds to a pseudo-single-phase flow model. $F L O W-3 D^{\circledR}$ offers different alternatives for the implementation of equations such as this last one, treating the problem as a two-fluid problem or as a pseudo-single-phase one. Since our focus is on the non-aerated flow region, we selected the last alternative in our computations. More research will be developed regarding this issue in the near future according to our research plans. 
We adopted 2D versions of the equations presented above, which agrees with the simulations developed by Savage and Johnson [75] and Johnson and Savage [54], albeit for smooth, conventional spillways.

\subsection{Location of the free surface}

The above equations are valid within a domain $\Omega$ which includes the flow in the stepped spillway and the stilling basin, and it is limited by the incoming flow in the tank, the outgoing flow downstream of the stilling basin, the solid boundary in the spillway, and the free surface (Fig. 3a). The location of the free surface is a priori unknown, involving the need to calculate that location each time step, starting from an initial condition.

The TruVOF (embedded in FLOW-3D ${ }^{\circledR}$; see Hirt and Nichols [48]) is used in this work to capture the free surface. TruVOF is a donor-acceptor algorithm and employs three key elements [16]. The first element is constituted by the definition and use of the $F$ function, which depicts the fractional volume of fluid occupying each cell; its value ranges from zero (no fluid in the volume) to one (cell completely filled with fluid). The free surface is defined to be located at a position pertaining to intermediate values of the fractional volume in the cells. A value of $F=0.5$ is usually employed for that purpose [39]. The second element is the use of an appropriate advection numerical method for the equation governing the transport of the VoF function (Eq. 7) that is designed to ensure a small numerical diffusion of the free surface. At each time step, the function $F$ is obtained by solving the following equation:

$$
\frac{\partial F}{\partial t}+\nabla \cdot\left(\underline{\bar{u}}_{m} F\right)=0
$$

in the entire domain [38]. Finally, an important third element is the application of boundary conditions at the free surface (Fig. 3b). Unlike in other methods published recently (see Matthews et al. [61,62] for example), the flow and transport equations are solved only in cells with liquid, because the gas is assumed to possess negligible inertia. The gas is considered only able of applying a normal pressure on a liquid surface (Fig. 3b). Once the free surface location is defined each time step, the model given by Eqs. 2-6 is numerically solved within the water domain limited by the free surface (Fig. 3b) while the air outside the free surface does not participate of the "active volumes" of the computation. The TruVOF method enjoys the following advantages: (a) minimum storage of information, since only one variable, $F$, has to be stored; (b) adequate (small) computational cost; and (c) good accuracy for fine meshes.

\subsection{Additional boundary conditions}

We specified pressure boundary conditions in both upstream and downstream boundaries, based on the water depths observed experimentally (Fig. 3). Although we did not have experimental information within the stilling basin, we included it in the computational domain to enforce the physical boundaries where we had pressure data. We checked that the selected boundary conditions did not produce spurious waves in the computational domain (see Storti et al. [78] for a discussion on boundary conditions for flows with a change in flow condition within the domain).

We imposed null velocities normal to the step walls [13,69], and employed the usual "wall functions" for the turbulence statistics [38]. These functions are [33,38,69]

$$
\left.k\right|_{w}=\frac{u_{*}^{2}}{\sqrt{c_{\mu}}} ;\left.\quad \varepsilon\right|_{w}=\frac{u_{*}^{3}}{\left(\kappa y_{1}\right)}
$$


where $u_{*}$ is the wall-friction (shear) velocity, obtained iteratively by the use of the semi-logarithmic velocity law, $\kappa$ is the von-Kármán constant, and $y_{1}$ is the normal distance perpendicular to the wall [39]. The steps developed to compute $u_{*}$ and the turbulence statistics at the wall are: (a) determination of the direction normal to the wall in the wall volume; (b) the cell-centered flow velocity at the wall volume is decomposed into parallel $\left(u_{\text {parallel }}\right)$ and perpendicular ( $\left.u_{\text {perpendicular }}\right)$ components; (c) the average distance to the wall, $y_{1}$, is calculated as half of the volume width in the direction normal to the wall; (d) $u_{*}$ is computed using $u_{\text {parallel }}$ and $y_{1}$ in an iterative way. Given the numerous simulations in which these wall functions have been used in the last decades $[33,38,69,72,82]$, we believe that they provide a tested description of the boundary conditions for turbulence statistics for this case (see discussion in Pope [69]).

Boundary conditions imposed at, and a sub-model for the air entrainment through the free surface are detailed below.

\subsection{Sub-model/boundary condition for the air entrainment through the free surface}

A sub-model included in the commercial code is able to simulate the natural entrainment of air due to turbulence at the free surface. When any disturbance of size $L_{T}$ at the free surface is associated with a larger energy per unit volume, $P_{T}$, than the energy of the stabilizing forces (related to gravity and the surface tension), $P_{d}$, the sub-model allows a volume of air to enter the mixture flow [47]. The equations of the sub-model are as follows:

$$
\begin{aligned}
& L_{T}=c_{\mu}\left(\frac{3}{2}\right)^{1 / 2} \frac{k^{3 / 2}}{\varepsilon} ; \quad P_{d}=\rho_{m} g_{n} L_{T}+\frac{\sigma}{L_{T}} ; \quad P_{T}=\rho_{m} k \\
& \text { If } P_{T}>P_{d}: \delta V=C_{\text {air }} A_{s}\left[\frac{2\left(P_{T}-P_{d}\right)}{\rho_{m}}\right]^{1 / 2}
\end{aligned}
$$

where $g_{n}$ is the component of the vector of the acceleration of gravity in the direction normal to the free surface; $\sigma$ is the surface tension; $C_{\text {air }}$ is a coefficient of proportionality; $A_{s}$ is the surface area; and $\delta V$ is the volume of air allowed to enter the flow through the free surface per unit time. According to Hirt [47], a good first guess is $C_{\text {air }}=0.5$, which assumes on average that air is trapped over about half the surface area of the raised disturbance.

\section{Numerical model: features and implementation of runs}

\subsection{Main features of the code}

In this research we used the commercial code $F L O W-3 D^{\circledR}$, which constitutes a general purpose CFD program [39]. The equations of the mathematical model presented above are solved by the method of finite volumes/finite differences in a Cartesian, staggered grid. The code has been employed to simulate flows through hydraulic structures (see, for instance, Bombardelli et al. [15,16], Savage and Johnson [75], Johnson and Savage [54]) and flows through river reaches and bends (see, for example, Wade et al. [81], Rodríguez et al. [73], Abad et al. [1]). In $F L O W-3 D^{\circledR}$, the tasks of building the grid and defining the geometry are completely independent. This property allows for modifications on the obstacles without making changes on the grid (e.g., for different configurations of the objects in the problem), 
or for modifications on the grid keeping the original geometry intact (e.g., for refinement of the solution).

The domain can be constituted by single- or multi-block grids. This last feature permits the optimization of the mesh in areas with complicated obstacle geometries, and reduces the memory requirements and the computational cost. Pressures, velocities and concentrations are computed separately in each grid block, and information from blocks is transferred among them. This exchange of data among blocks is done differently for pressures, velocities and other solution variables. While the pressures and velocities are interpolated linearly, the scalars and turbulence statistics are "overlaid" [7]. In these simulations we used multiple blocks.

The full geometry can be incorporated into $F L O W-3 D^{\circledR}$ through different methodologies: (a) a "solid modeler," which is based on the exploitation of general quadratic functions; (b) Computer-Aided-Design (CAD) files, usually through stereolithography (STL) files; or (c) topographic data (i.e., ASCII files with $x, y, z$ data). After both the geometry and the grid are defined, the FAVOR ${ }^{\mathrm{TM}}$ technique allows the obstacles to be embedded in the grid [49]. FAVOR $^{\mathrm{TM}}$ stands for Fractional Area/Volume Obstacle Representation and consists of the computations of areas and volumes obstructed to flow due to the solid boundaries: those area or volume fractions are incorporated in the model equations. More information can be found in Flow Science [39].

\subsection{Numerical model implementation: geometry, grid, and mesh-convergence tests}

The geometry was generated using AutoCAD, based on the dimensions of the physical model; it was then imported into the code as an STL file. The domain was discretized using ten blocks to optimize the mesh in accordance to the given geometry, as shown in Fig. 3a. The domain included a distance upstream of the face of the spillway to allow for a "buffer" zone for the boundary condition imposed at the upstream boundary (i.e., whereas the pressure was imposed, the velocities were not; see, for instance, Rodríguez et al. [73]). In order to assess the influence of such distance on the numerical results, we tested two domains with different "buffer" zone lengths: $2.5 \mathrm{~m}$ (short) and $4.5 \mathrm{~m}$ (extended). The runs were developed in a personal computer with a Pentium 2.66 Ghz processor and $8 \mathrm{~Gb}$ of RAM; the evolution in time was used as a relaxation to the final steady state. The steady state is checked through monitoring the flow kinetic energy displayed by the code in its Graphical User Interface (GUI). Steady state was typically reached after several stages of stop-restart of runs of a few tens of seconds of simulation time each.

Figure 4 displays velocity profiles at distances of $0.64,1.14$, and $1.34 \mathrm{~m}$ from the crest of the spillway, in order to compare the numerical results obtained with three meshes of 2.0 (Run 12), 2.2 (Run 43) and 2.4 (Run 44) million volumes, respectively, detailed in Table 2, for a $q_{w}$ of $0.18 \mathrm{~m}^{2} / \mathrm{s}$. Whereas the mesh with 2.0 million volumes was composed by cells of $3 \mathrm{~mm}$ in the $x$ direction and $4 \mathrm{~mm}$ in the vertical direction, the meshes with 2.2 and 2.4 million volumes were composed by cells of $2.85 \mathrm{~mm}$ in the $x$ direction and $3.8 \mathrm{~mm}$ in the vertical direction, and $2.7 \mathrm{~mm}$ in the $x$ direction and $3.6 \mathrm{~mm}$ in the vertical direction, respectively. Results show the condition pertaining to a final steady state. The three meshes yielded virtually the same results for the velocity profiles and the water depths, as seen in Fig. 4, meaning that a mesh-converged solution was attained (we were not interested in obtaining the mesh convergence rate). The mesh with 2.0 million volumes was then used throughout the simulations. 

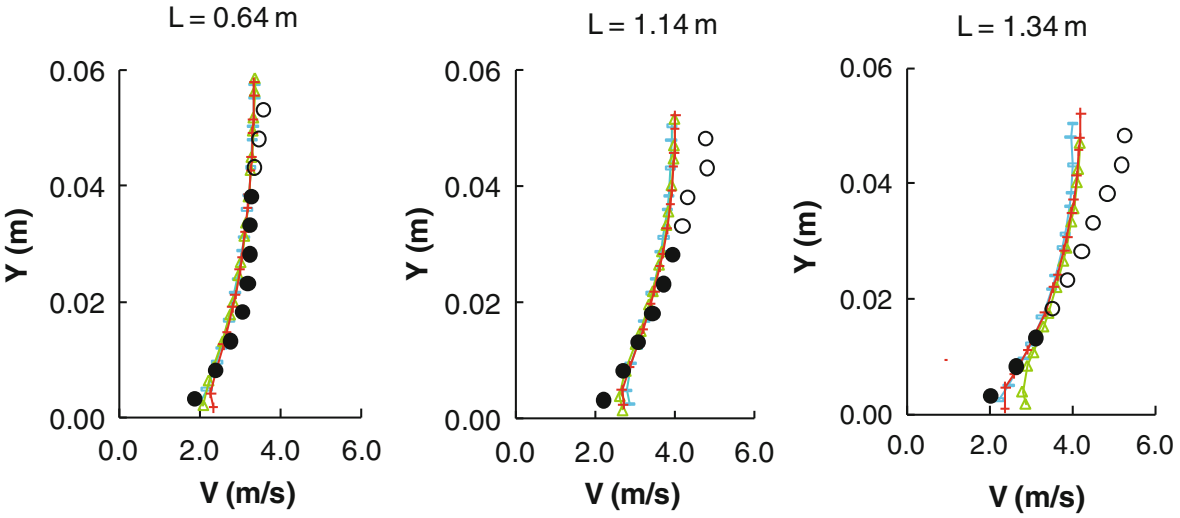

- Experimental 0 Experimental $\quad$ Run $12 \rightarrow$ Run $43 \rightarrow$ Run 44

(a)

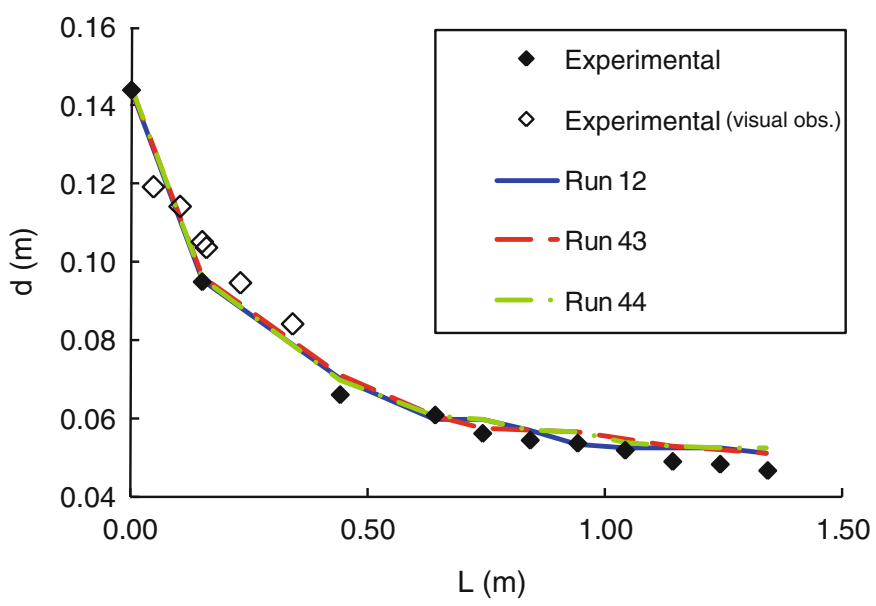

(b)

Fig. 4 Results of the mesh convergence analysis: comparison of results for three meshes of 2.0, 2.2 and 2.4 million volumes: a Water velocities at different distances from the crest of the spillway (unfilled symbols refer to points with measurements affected by either the unsteady motion of the free surface or the unsteadiness of the location of the inception point; filled symbols indicate points in good standing); $\mathbf{b}$ water levels at different distances from the crest of the spillway. $q_{w}=0.18 \mathrm{~m}^{2} / \mathrm{s}$

Table 2 Data on meshes for simulations with $F L O W-3 D^{\circledR}$ for assessment of mesh convergence $\left(q_{w}=\right.$ $\left.0.18 \mathrm{~m}^{2} / \mathrm{s}\right)$

\begin{tabular}{llll}
\hline Name & No. of cells of cells $(\mathrm{m})$ & Min. size of cells $(\mathrm{m})$ & Max. size of cells $(\mathrm{m})$ \\
\hline Run 12 & $2.0 \mathrm{E}+06$ & $3.00 \mathrm{E}-03$ & $4.00 \mathrm{E}-03$ \\
Run 43 & $2.2 \mathrm{E}+06$ & $2.85 \mathrm{E}-03$ & $3.80 \mathrm{E}-03$ \\
Run 44 & $2.4 \mathrm{E}+06$ & $2.70 \mathrm{E}-03$ & $3.60 \mathrm{E}-03$ \\
\hline
\end{tabular}



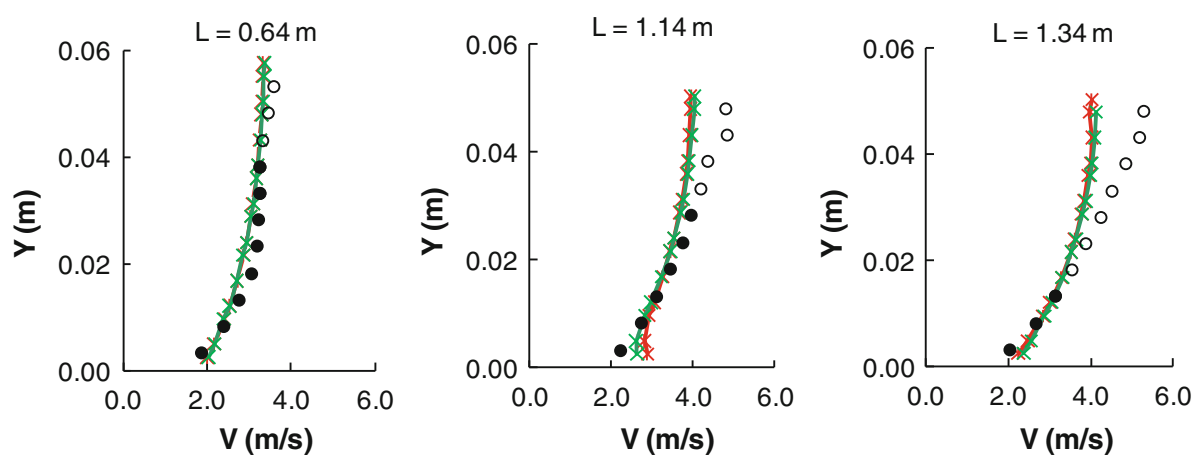

- Experimental $\bigcirc$ Experimental $-*-$ Short domain $*$ Extended domain

Fig. 5 Comparison among experimental and numerical results obtained for the "short" and "extended" domains, regarding water velocities. Unfilled symbols refer to points with measurements affected by either the unsteady motion of the free surface or the unsteadiness of the location of the inception point; filled symbols indicate points in good standing. $q_{w}=0.18 \mathrm{~m}^{2} / \mathrm{s}$

Figure 5 presents a comparison of modeled velocities at the same distances from the crest of the spillway specified in Fig. 4, showing that the "short" and "extended" domains offer virtually the same results, with the natural savings in computational time associated with the former. Differences among results with both runs were smaller than $2 \%$ in the local velocities and $0.5 \%$ in the water depths and volumetric flow rate (or discharge; see below), which we considered negligible.

\section{Comparison of experimental and numerical results}

5.1 Verification of the volumetric flow rate (discharge), water depth and velocity distribution

To verify that the model provided the right discharge, we integrated numerically the results of velocity in several flow cross sections, using the trapezoidal rule [19]. Relative differences among experimental and numerical values of discharge for the non-aerated flow region of the spillway were less than $5 \%$ (average difference of $2.4 \%$ ) for $q_{w}=0.18 \mathrm{~m}^{2} / \mathrm{s}$, which constitutes an excellent agreement, especially considering that this difference is within the experimental error in observing flow discharge. The same level of agreement was obtained for $q_{w}=0.08$ and $0.14 \mathrm{~m}^{2} / \mathrm{s}$.

Comparisons of measured and modeled water depths $(d)$ are presented in Fig. 6 for $q_{w}=0.18 \mathrm{~m}^{2} / \mathrm{s}$, where $L$ is measured from the crest of the spillway (Fig. 1). Visual observations of the flow in the physical model indicated that the time-averaged position of the free surface exhibited a slightly wavy pattern along the chute, particularly near the inception point. This is in agreement with observations from previous authors [26]. This feature was also noticed during the acquisition of data with the conductivity probe, the back-flushing Pitot tube, and the point gauges. Similar to the experimental data, a wavy pattern was obtained in the numerical result (Fig. 6). A very satisfactory agreement can be observed between both results. Differences between experimental and numerical results in Fig. 6 are less than 9\%. An assessment of the error in the location of the free surface from the numerical result can be 


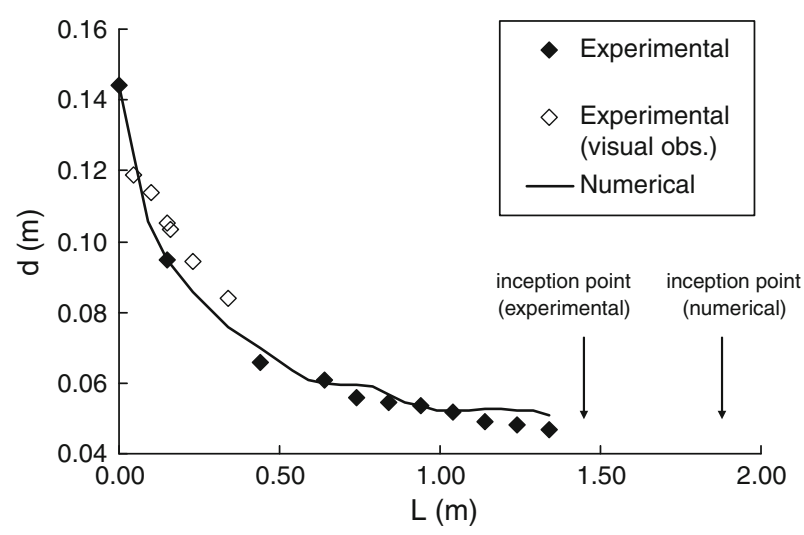

Fig. 6 Comparison among simulated and measured water flow depths. $q_{w}=0.18 \mathrm{~m}^{2} / \mathrm{s}$

made from the definition that $F L O W$ - $3 D^{\circledR}$ uses for that purpose (i.e., the value of $F=0.5$ ), and from considerations of mesh size. We estimated this error to be smaller than $1 \mathrm{~mm}$, which is much smaller than the measured depths in the physical model.

The shape of the velocity profiles obtained with $F L O W-3 D^{\circledR}$ (solid lines), presented in Fig. 7 for $q_{w}=0.18 \mathrm{~m}^{2} / \mathrm{s}$, follows relatively closely the experimental one. In general, it can be observed that good agreement has been obtained, especially for the filled symbols where the differences are mainly smaller than $10 \%$ (7\% on average). Notwithstanding this good agreement, the numerical solution seems to produce slightly more uniform velocity profiles than observed, which could in principle be associated with the pseudo-bottom normal diffusion generated by the turbulence closure. (The pseudo-bottom is defined as the surface tangent to the corners of the consecutive steps.) Differences may also stem from three-dimensional flow structures and effects that are not captured in a 2D simulation, such as vortex stretching and self-induced velocity which contribute to "dissipate" eddies in 3D (see Bombardelli et al. [18]). Similar agreement was obtained for other discharges, as shown below.

It is interesting also to notice that some of the simulated velocity profiles show a zone of almost constant velocity close to the pseudo-bottom. While such behavior has been observed in some experimental works in the past (see Gonzalez [42]; Boes and Hager [9]), not all works report it. Certainly, we did not find it in our experiments. More research is needed to clarify this issue.

Because upstream of the inception point the velocity outside of the boundary layer is given by $V_{\max }$, it is customary to consider a power-law velocity profile expressed by [26]:

$$
\frac{V}{V_{\max }}=\left(\frac{y}{\delta}\right)^{1 / N} \quad 0 \leq y / \delta \leq 1
$$

where $V_{\max }$ is the free-stream velocity; $y$ is the transverse coordinate originating at the pseudo-bottom; $\delta$ is the boundary layer thickness defined as the perpendicular distance from the pseudo-bottom to the point where the velocity is $0.99 V_{\max }$; and $N$ is an exponent, to be determined from experiments and numerical simulations. This assumes a self-similar behavior for the velocity profiles $[6,40]$.

Figure 8 presents the velocity profiles normalized by $V_{\max }$ for $q_{w}=0.18 \mathrm{~m}^{2} / \mathrm{s}$. Numerical results of this paper show significantly better agreement with experimental data than those presented by Cheng et al. [31] for the air-water flow region, as expected. The agreement is 

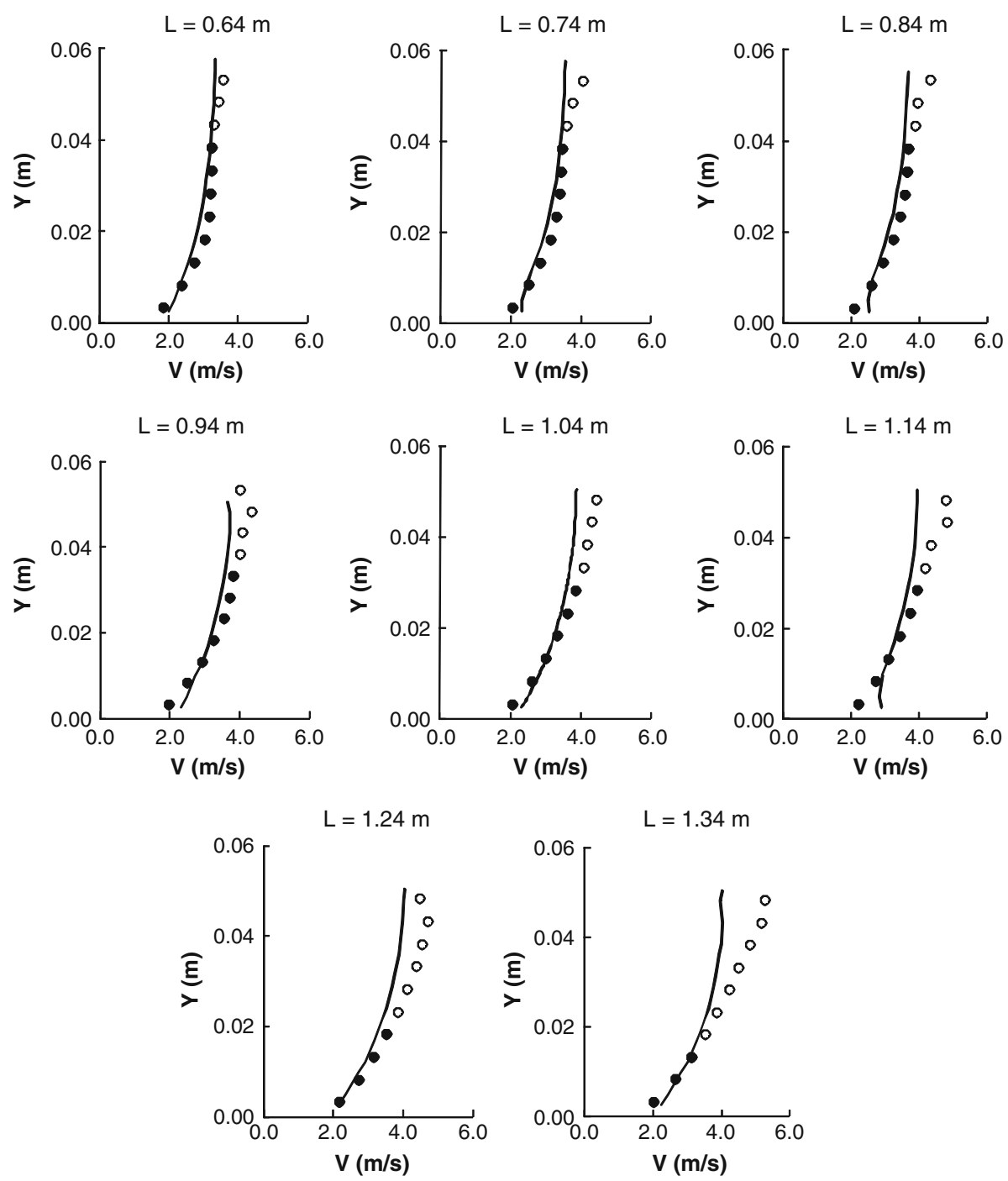

- Experimental $\circ$ Experimental - Numerical

Fig. 7 Velocity distribution upstream of the point of inception: comparison among simulated and measured results. Unfilled symbols refer to points with measurements affected by either the unsteady motion of the free surface or the unsteadiness of the location of the inception point; filled symbols indicate points in good standing. $q_{w}=0.18 \mathrm{~m}^{2} / \mathrm{s}$

of the same nature throughout the spillway. Velocity profiles present similar distributions to those observed by Amador et al. [3] for the non-aerated flow region. In the step cavities, recirculating zones become well defined (not shown herein).

Figure 9 presents comparisons between observed and modeled velocity profiles for specific discharges of $0.08,0.14$ and $0.18 \mathrm{~m}^{2} / \mathrm{s}$, at 0.64 and $0.74 \mathrm{~m}$ from the crest of the spillway. It is possible to see that the agreement obtained is of the same satisfactory quality as explained above. For $q_{w}=0.08 \mathrm{~m}^{2} / \mathrm{s}$, a smaller number of points was observed experimentally because 

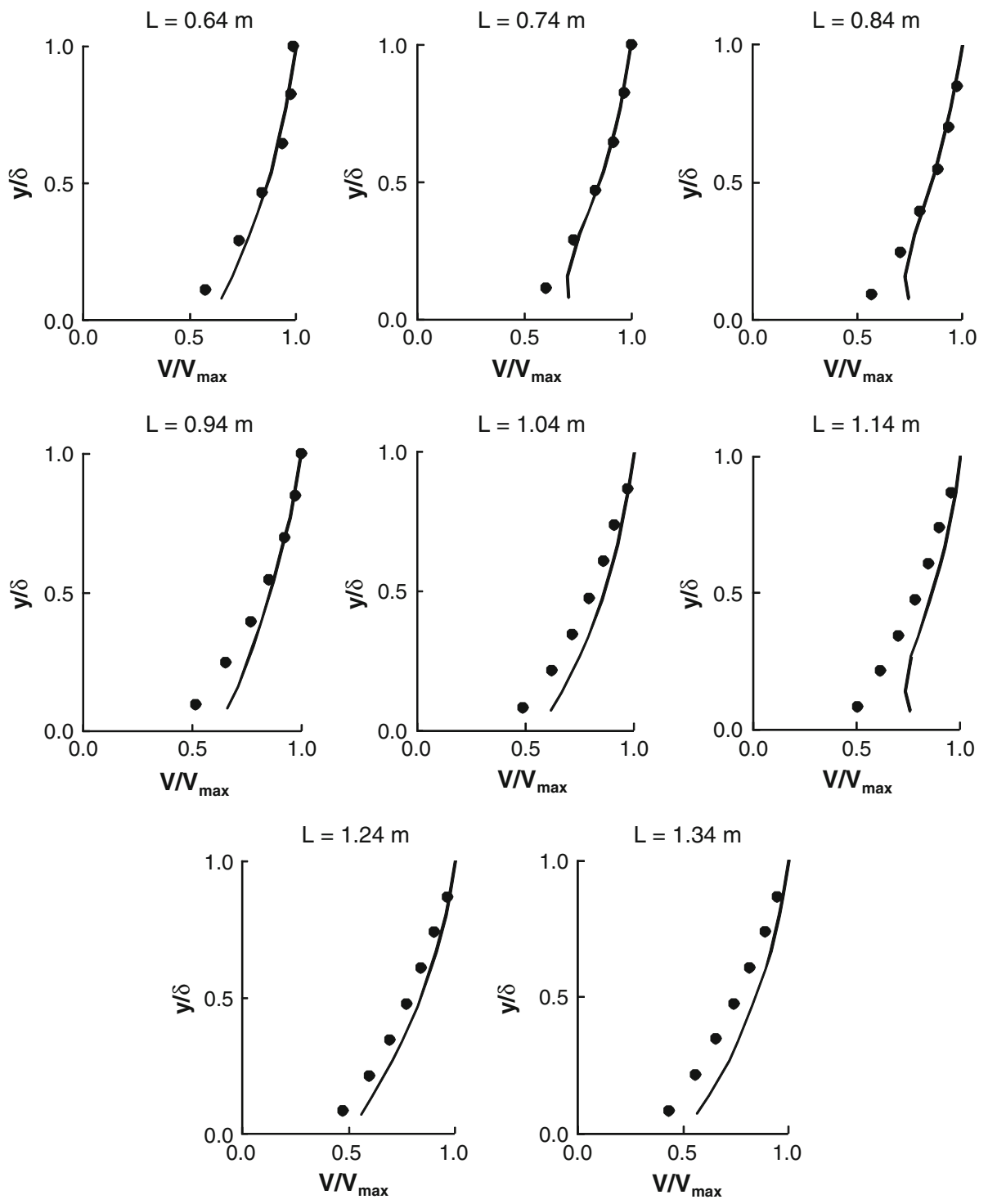

- Experimental - Numerical

Fig. 8 Normalized velocity distribution upstream of the point of inception: comparison among simulated and measured results. $q_{w}=0.18 \mathrm{~m}^{2} / \mathrm{s}$

of the shallower water depth. Similar level of agreement was obtained for a stepped spillway with steps of $8 \mathrm{~cm}$, and a specific discharge of $0.18 \mathrm{~m}^{2} / \mathrm{s}$ (not shown herein).

From both the experimental and numerical results, we obtained values of the exponent $N$ of Eq. 11 equal to 3.4 and 5.4, respectively. Whereas the experimental value of the exponent is close to the exponents reported for the non-aerated or aerated regions in steep stepped chutes $[2,26,56,63,71]$, the numerical counterpart is closer to the exponent obtained for less 

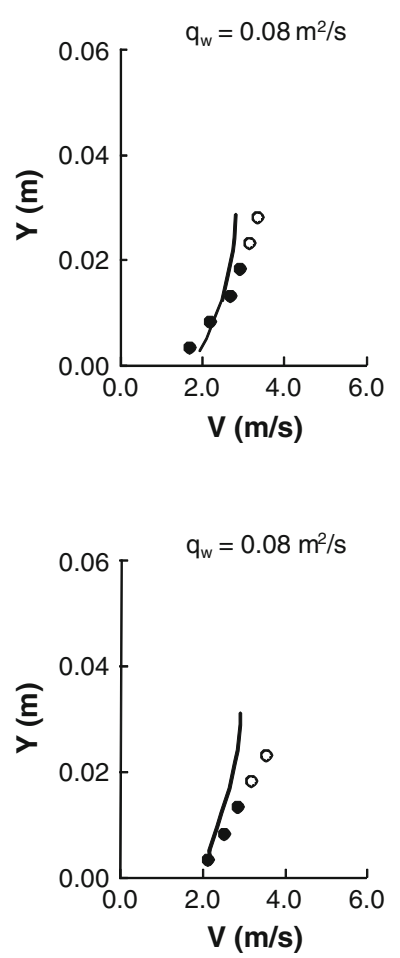

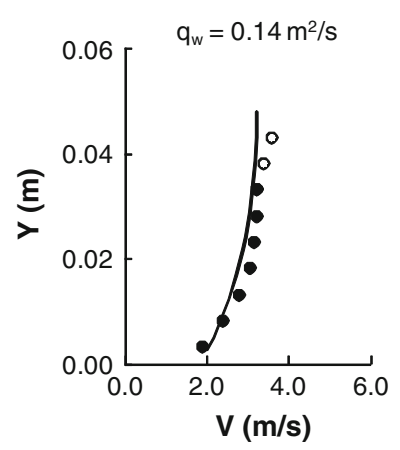

(a)

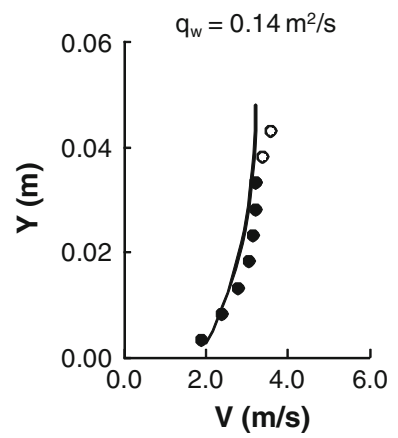

(b)
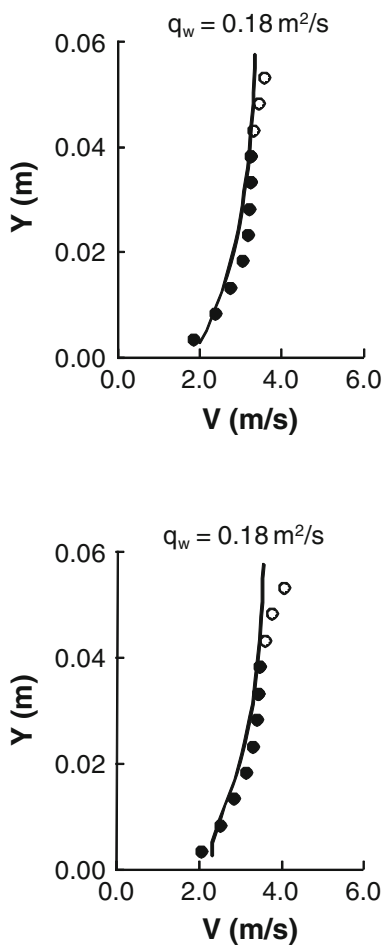

\section{- Experimental $O$ Experimental - Numerical}

Fig. 9 Comparison among experimental and numerical velocities for unit discharges of $0.08,0.14$ and 0.18 $\mathrm{m}^{2} / \mathrm{s}$ for: $\mathbf{a} L=0.64 \mathrm{~m}$ and $\mathbf{b} L=0.74 \mathrm{~m}$. Unfilled symbols refer to points with measurements affected by either the unsteady motion of the free surface or the unsteadiness of the location of the inception point; filled symbols indicate points in good standing

steep slopes, either on the non-aerated $[64,66]$ or on the gradually varied or quasi uniform aerated flow regions [4,9]. In turn, Felder and Chanson [37] found a value of $N=10$ for the velocity profile in the aerated region.

\subsection{Boundary layer development}

Figure 10 presents a fairly good agreement between the normalized boundary layer thickness $(\delta / L)$ obtained by definition from the experiments (open symbols), and from the simulations with $F L O W-3 D^{\circledR}$ (filled symbols), for several values of the normalized distance along the spillway $\left(L / k_{s}\right) . k_{s}$ is the roughness height perpendicular to the pseudo-bottom, $k_{s}=h \cos \theta$, with $h$ denoting the step height; $\theta$ is the angle of the spillway; and $L$ is measured from the crest of the spillway. Similarly to smooth spillways [21], the growth of the boundary layer can be estimated by an equation of the type

$$
\frac{\delta}{L}=a\left(\frac{L}{k_{s}}\right)^{-b}
$$

where $a$ and $b$ are real numbers. For $q_{w}=0.18 \mathrm{~m}^{2} / \mathrm{s}$, we obtained $a=0.223$ and $b=0.497$ from experiments (for $26.7<L / k_{s}<55.8$ ) and $a=0.27$ and $b=0.55$ from numerical 
Fig. 10 Development of the boundary layer: comparison among simulated and measured results, regressions to the data, and formulations of Chanson [26] and Amador [2]. $q_{w}=0.18 \mathrm{~m}^{2} / \mathrm{s}$

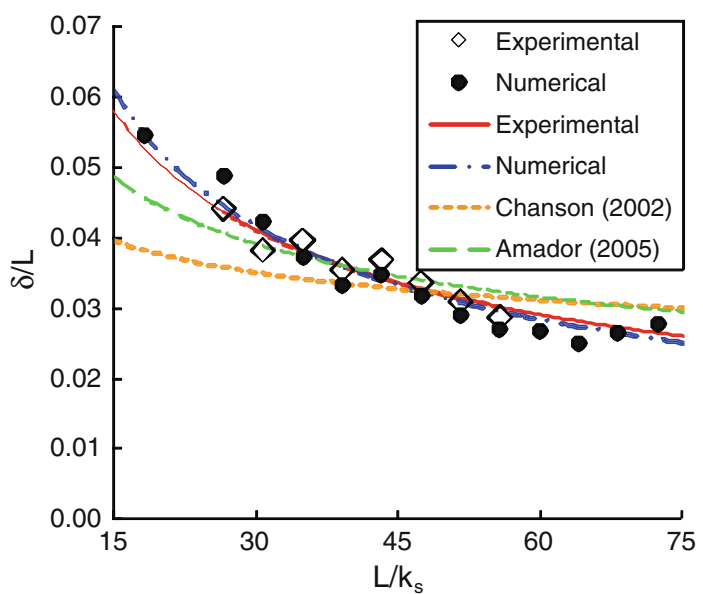

data (for $18.5<L / k_{s}<72.5$ ). The expressions proposed by Chanson [26] and Amador [2] for $\frac{\delta}{L}$ are also presented in Fig. 10. The formula proposed by Chanson [26] is based on model and prototype data tested for a wide range of angles and conditions. Amador's equation was developed from experiments undertaken in a $1 \mathrm{~V}: 0.8 \mathrm{H}$ stepped spillway, with $a=0.112$ and $b=0.309$. The agreement between the data of the current paper with Amador's expression or Chanson's equation is fairly good for $L / k_{s}$ values larger than approximately 40 . For lower $L / k_{s}$ values, the agreement with Amador's expression was better than the agreement with Chanson's equation. To show the different behaviors, all formulations are presented in Fig. 10 for the range $15<L / k_{s}<75$. (Outside of their domain of application, the expressions are presented with thinner lines). The discrete nature of the velocity profiles (both experimental and numerical) increases the difficulty in estimating the boundary layer thickness for each cross section along the spillway, contributing to the differences observed. In addition, it is worth highlighting that the values of $b$ obtained in our work and elsewhere are larger than the value of 0.13 found for smooth chutes [32], denoting the well-known faster development of the boundary layer in stepped spillways.

The inception point of air entrainment corresponds to the section where the growing boundary layer reaches the free surface. The location of the inception point was obtained from the numerical results comparing the spatial variation of the water flow depth and the boundary layer thickness (Fig. 11).

In Table 3, it is possible to see that the numerical result of $L_{i}$, the location of the inception point, compares fairly well with the experimental relations presented by Chanson [26]. Although numerical and experimental water depth and boundary layer thickness results are close, the spatial variations of the numerical predictions of water depth and $\delta$ are slightly smaller than the experimental counterparts, contributing to the observed difference in $L_{i}$. In addition, a slightly greater depth at the inception point, $d_{i}$, was obtained from Chanson's regressions.

\subsection{Turbulence statistics}

TKE is generated in the steps and in other parts of the flow through the velocity gradients $[69,72]$. Numerical predictions show an increase in TKE along the spillway, for any given distance from the pseudo-bottom (Fig. 12a), which is the result of the development of the 


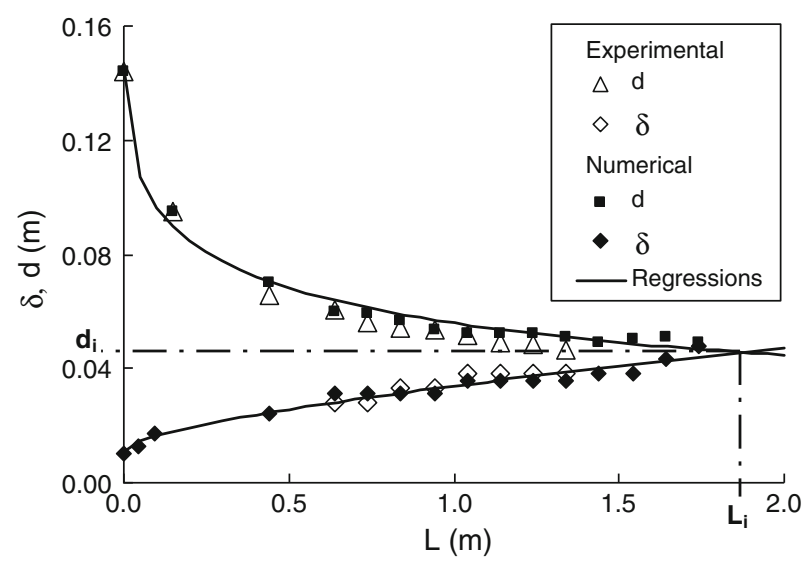

Fig. 11 Development of the boundary layer and variation of the water depth. Estimation of the inception point depth and location. $q_{w}=0.18 \mathrm{~m}^{2} / \mathrm{s}$

Table 3 Comparison of measured and modeled results regarding the depth and location of the inception point

\begin{tabular}{llc}
\hline Source & $L_{i}(\mathrm{~m})$ & $d_{i}(\mathrm{~m})$ \\
\hline Regression [26] & 1.75 & 0.053 \\
Experimental result & 1.44 & 0.046 \\
Numerical result & 1.87 & 0.046 \\
\hline
\end{tabular}

$L_{i}=(h \cos \theta) 9.719(\sin \theta)^{0.0796} F_{*}^{0.713}$ (location of the inception point)

$d_{i}=(h \cos \theta) 0.4034(\sin \theta)^{-0.04} F_{*}^{0.592}$ (depth of the inception point)

$F_{*}=q_{w} / \sqrt{g \sin \theta(h \cos \theta)^{3}}$ (Froude number)

$h$ : step height; $\theta$ : angle of the spillway; $q_{w}$ : discharge per unit width; $g$ : acceleration of gravity

${ }^{\text {a }}$ See also [37]

boundary layer. Figure 12b and c show details of Fig. 12a, depicting higher values of TKE at the center of the step cavities. These results are qualitatively similar to those presented by Cheng et al. [30,31], obtained from a numerical study of the air-water flow region. In addition, these results agree in shape with the experimental evidence presented by Amador et al. [3] acquired with the use of a PIV system.

Figure 13 presents contours of the computed dissipation rate of TKE. The patterns are similar to those presented for the TKE, possibly indicating that the steps are mostly regions of both creation and dissipation of TKE, in spite of the fact that some transfer of TKE between steps occurs. Figures 12 and 13 also help identifying the development of the so-called "roughness layer," akin to wall flows with large roughness elements (see Jimenez [53] for a detailed discussion on the influence of roughness on the flow).

\section{Sensitivity analyses of the numerical simulations}

In order to explore the influence of diverse modeling parameters and sub-models on the results, several additional runs were developed. 


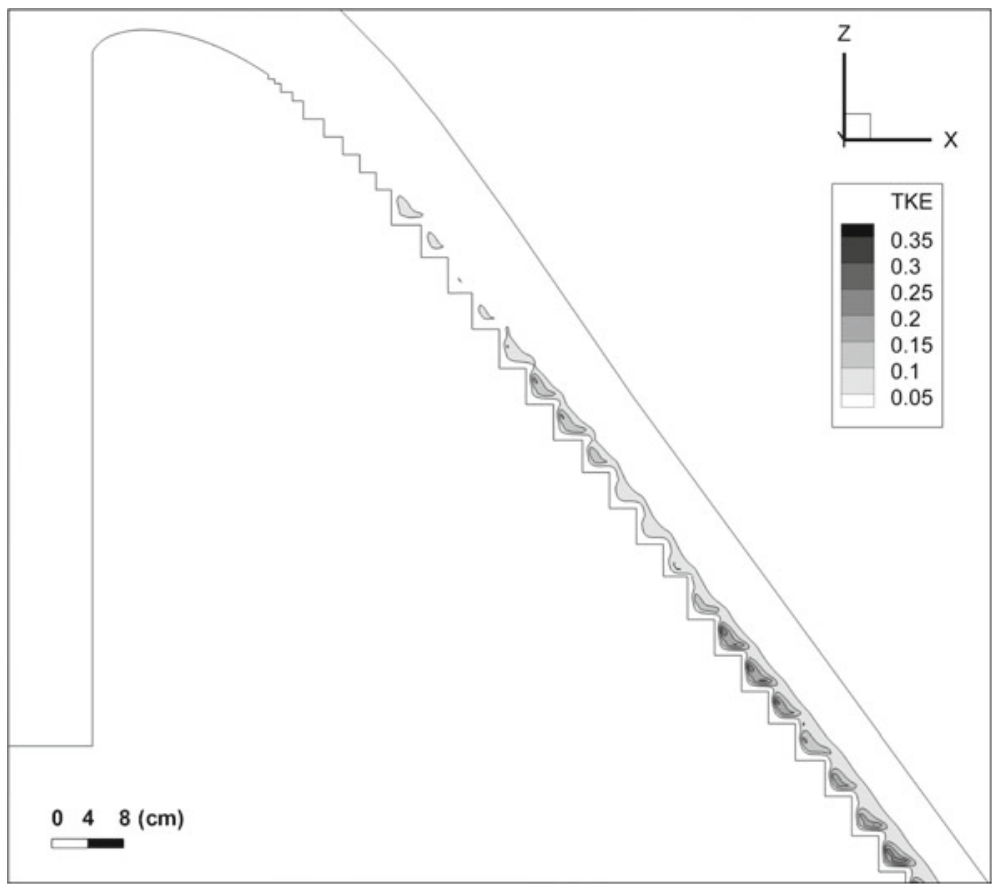

(a)

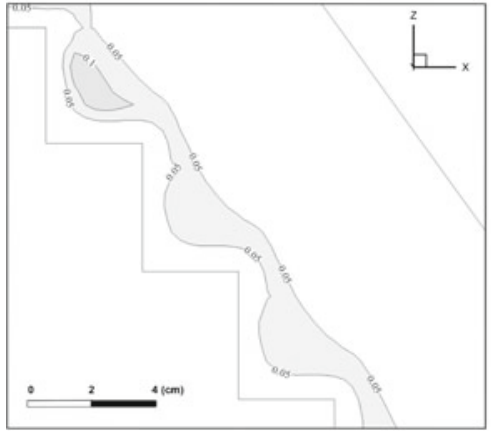

(b)

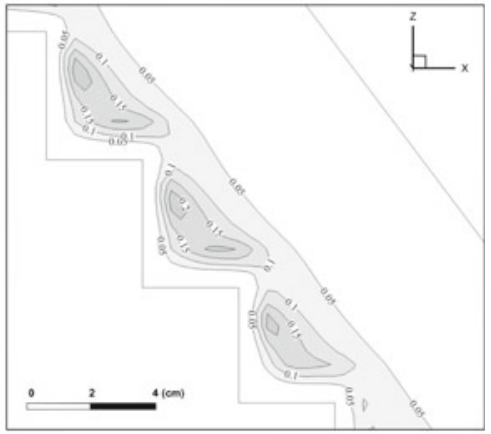

(c)

Fig. 12 Field of turbulent kinetic energy (TKE) obtained via numerical simulations (in $\mathrm{m}^{2} / \mathrm{s}^{2}$ ): a Evolution of the TKE in the non-aerated region of the spillway; $\mathbf{b}$ detail of TKE at steps 17, 18 and 19; $\mathbf{c}$ detail of TKE at steps 22,23 and 24. Contours show asymmetry in the steps, as observed experimentally [26]. $q_{w}=0.18 \mathrm{~m}^{2} / \mathrm{s}$

\subsection{Turbulence models and turbulence mixing length}

Simulations performed with the $k-\varepsilon$ model and the RNG $k-\varepsilon$ model $[83,84]$ provided very similar results (Fig. 14). Very small differences of about $1 \%$ in the local velocities and water flow depths, and of less than $0.5 \%$ in the discharges, were observed. For this reason, even if the RNG $k-\varepsilon$ model is in general regarded as having wider applicability than the $k-\varepsilon$ model, the present study shows that the $k-\varepsilon$ model offers as accurate results of velocities, water flow depth and discharge as the RNG $k-\varepsilon$ model for the stepped spillway problem. 


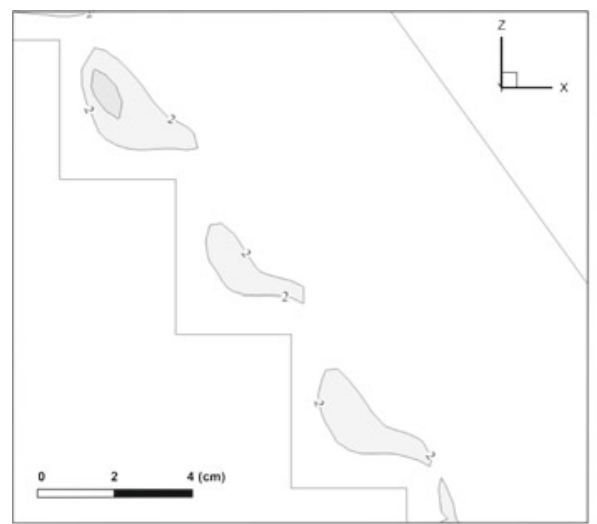

(a)

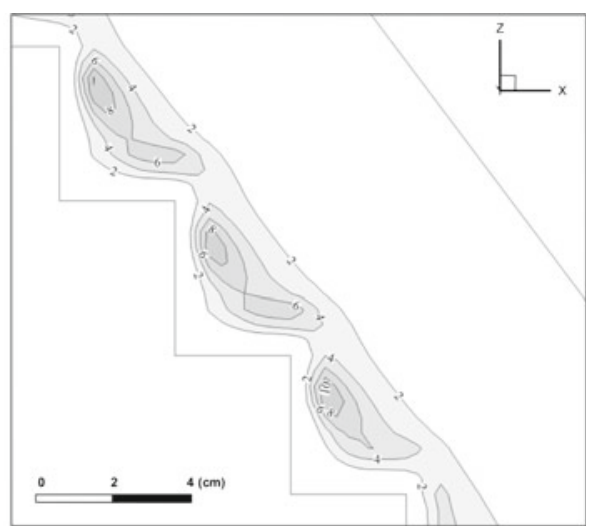

(b)

Fig. 13 Field of dissipation rate of TKE obtained via numerical simulations (in $\mathrm{m}^{2} / \mathrm{s}^{3}$ ): a detail of dissipation rate of TKE at steps 17,18 and 19; $\mathbf{b}$ detail of dissipation rate of TKE at steps 22,23 and $24 . q_{w}=0.18 \mathrm{~m}^{2} / \mathrm{s}$
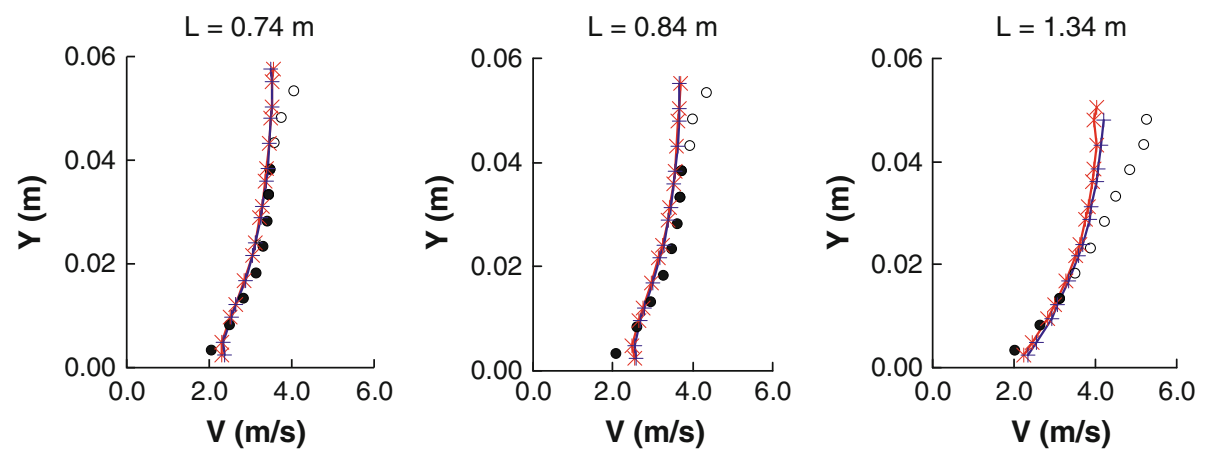

- Experimental $\circ$ Experimental $*$ k-e $\quad+$ RNG

Fig. 14 Sensitivity analysis corresponding to the turbulence model: Comparison among experimental and numerical results obtained using the $k-\varepsilon$ and RNG $k-\varepsilon$ turbulence models regarding water velocities. Unfilled symbols refer to points with measurements affected by either the unsteady motion of the free surface or the unsteadiness of the location of the inception point; filled symbols indicate points in good standing. $q_{w}=0.18 \mathrm{~m}^{2} / \mathrm{s}$

Furthermore, it can be noticed that the turbulent diffusion in the pseudo-bottom normal direction is similar for both closures.

$F L O W-3 D^{\circledR}$ includes a turbulent mixing length (TLEN) for the $k-\varepsilon$ and RNG $k-\varepsilon$ turbulence models to regulate the dissipation rate of TKE and the eddy dynamic viscosity (see also Johnson and Savage [54]). If TLEN is too high (low), the dissipation rate can be under- (over-) predicted and the eddy dynamic viscosity can be unrealistically high (low) (recall Eq. 5). Two different simulations were performed, one with the default value used by $F L O W-3 D^{\circledR}$ (which is $7 \%$ of the smallest domain dimension) and another with TLEN equal to $7 \%$ of the flow depth in the non-aerated flow region of the spillway. This last value is about 50 times smaller than the default value. No noticeable differences were observed among the results of the two simulations. The relative differences in the velocities were usually of about $0.3 \%$, and the relative differences in the discharges and water depths were smaller than $1 \%$. 

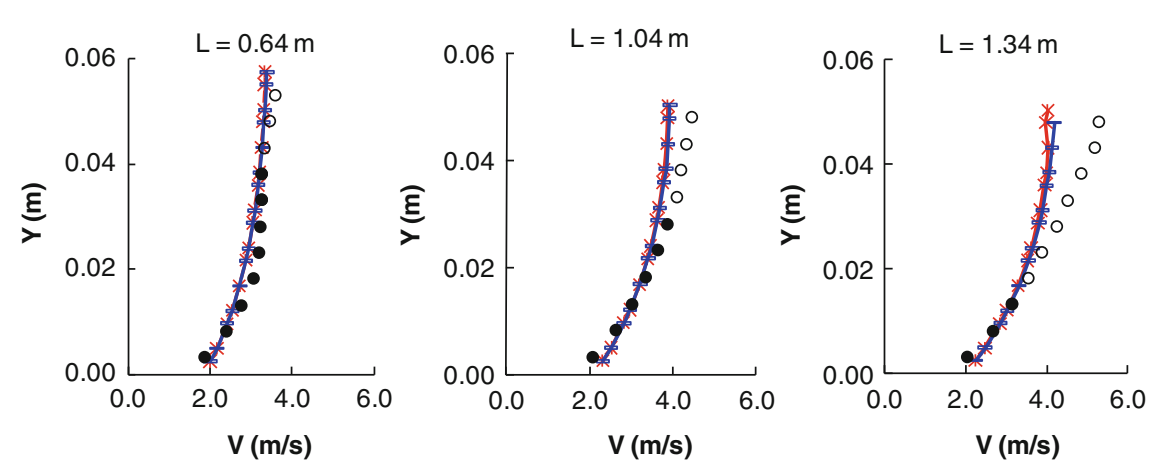

- Experimental $\circ$ Experimental $*$ Model of air not activated - Model of air activated

Fig. 15 Sensitivity analysis corresponding to the sub-model of air incorporation: Comparison among experimental and numerical results obtained with and without the sub-model of air incorporation regarding water velocities. Unfilled symbols refer to points with measurements affected by either the unsteady motion of the free surface or the unsteadiness of the location of the inception point; filled symbols indicate points in good standing. $q_{w}=0.18 \mathrm{~m}^{2} / \mathrm{s}$

\subsection{Sub-model for air entrainment}

Almost no difference was observed among the results with and without the activation of the sub-model for air-entrainment in the non-aerated region of the spillway, as expected (Fig. 15). In the runs shown herein, the gas was assumed to move at the velocity of the mixture in all directions. Discharges, water flow depths, and TKE values also gave similar results. This constitutes a much needed check to test the correctness of the computations.

\subsection{Evaluation of the computational results and theoretical models}

This paper provided an assessment of the non-aerated region of the skimming flow over steep stepped spillways, and completely characterized the flow features. Numerical simulations offer assistance to the design of this type of structures at the time they provide information on the flow details. Although some authors have decided to address the aerated flow from the start, focusing on the non-aerated region seems to be a natural first step in building more complex models. The ultimate interest is to have a set of complete models for the characterization of velocities, water levels, air concentrations and turbulence statistics in the entire spillway.

Throughout the non-aerated portion of the spillway, model predictions offered an accurate description of velocity profiles, of boundary layer development and of water depths. The model also predicted fairly well the location of the inception point and its depth for three discharges, taking into account the complex nature of the phenomenon. This suggests that the selected theoretical model is adequate for the non-aerated region, and that the numerical integration has been adequate.

Having said that, it becomes clear that this theoretical model needs improvement for the aerated region in order to be able to capture the increase of flow depth due to air entrainment, the non-dilute nature of the two-phase flow, the combination of the water/bubble and air/drop flows, and the interaction of phases [26]. The current theoretical model can provide only a slight increase in the flow depth in the aerated region and can offer air concentrations only accurate close to the pseudo-bottom. We are currently at the development stage of those more sophisticated models which, naturally, fall outside of the scope of this paper. Jha and Bombardelli [52] have very recently addressed the non-dilute sediment-laden flow in open 
channels with success and, thus, such work is a good starting point for our developments. We believe that the incorporation of more formal two-phase flow theories to the current model may yield the desired answers.

\section{Conclusions}

This paper has addressed the flow in steep stepped spillways. Our work focused on the non-aerated portion of skimming flows. Although flows in stepped spillways are usually characterized by high air concentrations concomitant with high rates of energy dissipation, the non-aerated region becomes important in small dams and/or spillways with high specific discharges.

Experiments combined with numerical simulations confirmed the wavy pattern of the free surface, especially close to the inception point. The two results showed a very satisfactory agreement. Results on the development of the boundary layer in this paper were not significantly different from results reported by other authors for moderate to large normalized distances along the chute; however, in the upstream reach of the spillway, near the crest, differences increased. Our results put forward values of the exponents $a$ and $b$, of the equation for the boundary-layer development, equal to $a=0.223$ and $b=0.497$ (experiments) and $a=0.27$ and $b=0.55$ (numerical result). In turn, the exponents of the self-similar velocity profiles were found to be in agreement with published results for similar geometric and flow conditions, varying in our case between 3.4 (experiments) and 5.4 (numerical).

The runs developed in this paper show that the use of a $k-\varepsilon$ model combined with the TruVOF method allow for an accurate representation of the flow features in the non-aerated region of the structure. No significant differences were observed in the simulations with this closure and the $k-\varepsilon$ RNG model. The use of the TruVOF, in particular, allows for an accurate yet economic technique which proves to be superior to re-meshing or to other versions of the method which solve for both the water and air flows. Further, the multi-block gridding feature embedded in $F L O W-3 D^{\circledR}$, which helps in optimizing the mesh, was crucial for saving computational time, and showed a clear advantage with respect to other techniques in other software packages.

Acknowledgments Fabián Bombardelli gratefully acknowledges the support of the California Department of Water Resources (DWR), through Award 4600007984 TO BD01, and the California Water Resources Control Board (CAWRCB), through Award 06-447-300 TO 5. Inês Meireles was a Visiting Scholar at the University of California, Davis, during the months of September 2007-March 2008, and was financially supported by a Fulbright/FLAD Research Grant. This support is gratefully acknowledged. The financial support granted by INAG, Portuguese Water Institution (Project 2003/2029/INAG), and by the Portuguese Foundation for Science and Technology (FCT), through Project PTDC/ECM/108128/2008, is also gratefully acknowledged. Currently, Inês Meireles is supported by FCT, Grant No. SFRH/BD/38003/2007.

Open Access This article is distributed under the terms of the Creative Commons Attribution Noncommercial License which permits any noncommercial use, distribution, and reproduction in any medium, provided the original author(s) and source are credited.

\section{References}

1. Abad JD, Rhoads BL, Guneralp I, García MH (2008) Flow structure at different stages in a meander bend with bendway weirs. J Hydraul Eng ASCE 134(8):1052-1063

2. Amador A (2005) Comportamiento Hidráulico de los Aliviaderos Escalonados en Presas de Hormigón Compactado. Ph.D. thesis, UPC, Barcelona, Spain (in Spanish) 
3. Amador A, Sanchez-Juni M, Dolz J (2006) Characterization of the non-aerated flow region in a stepped spillway by PIV. J Fluid Eng ASME 138(6):1266-1273

4. André S (2004) High velocity aerated flows over stepped chutes with macro-roughness elements. Ph.D. thesis, EPFL, Lausanne, Switzerland

5. Arantes EJ (2007) Caracterização do Escoamento sobre Vertedouros em Degraus via CFD. Ph.D. thesis, EESC/USP, São Carlos, Brazil (in Portuguese)

6. Barenblatt GI (1996) Scaling, self-similarity, and intermediate asymptotics. Cambridge University Press, Cambridge

7. Barkhudarov MR (2004) Multi-block gridding technique for Flow-3D. Flow Science Technical Notes, Flow Science, Inc, TN59, available online

8. Bhuiyan ABM, Hey R (2007) Computation of three-dimensional flow field created by weir-type structures. Eng Appl Comput Fluid Mech 1(4):350-360

9. Boes RM, Hager WH (2003) Two phase flow characteristics of stepped spillways. J Hydraul Eng ASCE 129(9):661-670

10. Boes RM, Hager WH (2003) Hydraulic design of stepped spillways. J Hydraul Eng ASCE 129(9):671679

11. Bombardelli FA (2003) Characterization of coherent structures from parallel, LES computations of wandering effects in bubble plumes. In: Bizier P, DeBarry P (eds) Proceedings of the 2003 world water and environmental resources congress. Environmental \& Water Resources Institute (EWRI), ASCE, Philadelphia (in CD)

12. Bombardelli FA (2004) Turbulence in multiphase models for aeration bubble plumes. Ph.D. thesis, University of Illinois at Urbana-Champaign

13. Bombardelli FA (2010) Water distribution systems. In: Fernando HJ (ed) Chapter 41 in Environmental fluid mechanics (in press)

14. Bombardelli FA, Jha SK (2009) Hierarchical modeling of dilute, suspended-sediment transport in open channels. Environ Fluid Mech 9(2):207-230

15. Bombardelli FA, García MH, Caisley ME (2000) 2-D and 3-D numerical simulation of abrupt transitions in open-channel flows. Application to the design of canoe chutes. In: Proceedings of the 4th international conference on hydroinformatics IAHR, Iowa City, IA, USA (in CD)

16. Bombardelli FA, Hirt CW, García MH (2001) Discussion on computations of curved free surface water flow on spiral concentrators by Matthews et al. J Hydraul Eng ASCE 127(7):629-631

17. Bombardelli FA, Buscaglia GC, Rehmann CR, Rincón LE, García MH (2007) Modeling and scaling of aeration bubble plumes: a two-phase flow analysis. J Hydraul Res IAHR 45(5):617-630

18. Bombardelli FA, Cantero MI, García MH, Buscaglia GC (2009) Numerical aspects of the simulation of discontinuous saline underflows: the lock-exchange problem. J Hydraul Res IAHR 47(6):777-789

19. Burden RL, Faires JD (2004) Numerical analysis, 8th ed. Brooks-Cole Publishing, Pacific Grove

20. Buscaglia GC, Bombardelli FA, García MH (2002) Numerical modeling of large scale bubble plumes accounting for mass transfer effects. Int J Multiph Flow 28:1763-1785

21. Cain P, Wood IR (1981) Measurements of self-aerated flow on a spillway. J Hydraul Eng ASCE 107(HY11):1407-1424

22. Caisley ME, Bombardelli FA, García MH (1999) Hydraulic model study of a canoe chute for low-head dams in Illinois. Civil Engineering Studies, Hydraulic Engineering Series No-63, University of Illinois at Urbana-Champaign

23. Carvalho R, Amador A (2008) Physical and numerical investigation of the skimming flow over a stepped spillway. In: Proceedings of the 3rd IAHR international symposium on hydraulic structures, Nanjing, China, pp 1767-1772

24. Chamani MR, Rajaratnam N (1999) Characteristics of skimming flow over stepped spillways. J Hydraul Eng ASCE 125(4):361-368

25. Chanson H (2001) Hydraulic design of stepped spillways and downstream energy dissipators. Dam Eng 11(4):205-242

26. Chanson H (2002) The hydraulics of stepped chutes and spillways. Balkema, Lisse

27. Chanson H (2009) Turbulent air-water flows in hydraulic structures: dynamic similarity and scale effects. Environ Fluid Mech 9(2):125-142

28. Chatila J, Tabbara M (2004) Computational modeling of flow over an ogee spillway. Comput Struct 82:1805-1812

29. Chen Q, Dai G, Liu H (2002) Volume of fluid model for turbulence numerical simulation of stepped spillway overflow. J Hydraul Eng ASCE 128(7):683-688

30. Cheng X, Luo L, Zhao W (2004a) Study of aeration in the water flow over stepped spillway. In: Proceedings of the world water congress 2004, ASCE, Salt Lake City, UT, USA 
31. Cheng X, Luo L, Zhao W, Li R (2004b) Two-phase flow simulation of aeration on stepped spillway. Prog Nat Sci 14(7):626-630

32. Chow VT (1959) Open-channel hydraulics. McGraw-Hill, New York

33. Chung TJ (2006) Computational fluid dynamics. Cambridge University Press, New York

34. Crowe C, Sommerfeld M, Tsuji Y (1998) Multiphase flows with droplets and particles. CRC Press, Boca Raton

35. Dargahi B (2006) Experimental study and 3D numerical simulations for a free-overflow spillway. J Hydraul Eng ASCE 132(9):899-907

36. Drew DA, Passman SL (1999) Theory of multicomponent fluids. Volume 135 of Applied mathematical sciences. Springer, New York

37. Felder S, Chanson H (2009) Energy dissipation, flow resistance, and gas liquid interfacial area in skimming flows on moderate-slope stepped spillways. Environ Fluid Mech 9(4):427-441

38. Ferziger JH, Peric M (2002) Computational methods for fluid dynamics. Springer, Berlin

39. Flow Science, Inc (2008) FLOW-3D user's manual, version 9.3. Flow Science, Inc, Los Alamos

40. Gioia G, Bombardelli FA (2002) Scaling and similarity in rough channel flows. Phys Rev Lett 88(1):014501

41. Gomes JF (2006) Campo de Pressões: Condições de Incipiência à Cavitação em Vertedouros em Degraus com Declividade 1V:0,75H. Ph.D. thesis, UFRGS, Porto Alegre, Brazil (in Portuguese)

42. Gonzalez C (2005) An experimental study of free-surface aeration on embankment stepped chutes. Ph.D. thesis, University of Queensland, Brisbane, Australia

43. Gonzalez C, Chanson H (2007) Hydraulic design of stepped spillways and downstream energy dissipators for embankment dams. Dam Eng XVII(4):223-244

44. Gonzalez C, Chanson H (2008) Turbulence and cavity recirculation in air-water skimming flows on a stepped spillway. J Hydraul Res IAHR 46(1):65-72

45. Hager W, Boes RM (2000) Backwater and drawdown curves in stepped spillway flow. In: Proceedings of the 1st international workshop on hydraulics of stepped spillway, Zurich, Switzerland. A.A. Balkema Publisher, Rotterdam, pp 129-136

46. Higgs J, Frizell KW (2004) Investigation of the lake plant pump station-Lower Colorado River Authority. Hydraulic Laboratory Report HL-2004-02, Denver Technical Center, Bureau of Reclamation, United States Department of the Interior, Denver, CO, December, 2004

47. Hirt CW (2003) Modeling turbulent entrainment of air at a free surface. Technical Note 61, Flow Science, Inc (FSi-03-TN61)

48. Hirt CW, Nichols BD (1981) Volume of fluid (VOF) method for the dynamics of free boundaries. J Comput Phys 39:201-225

49. Hirt CW, Sicilian JM (1985) A porosity technique for the definition of obstacles in rectangular cell meshes. In: Proceedings of the 4th international conference on ship hydro-dynamics. National Academy of Science, Washington, DC

50. Ho DKH, Cooper BW, Riddette KM, Donohoo SM (2006) Application of numerical modelling to spillways in Australia. In: Berga L et al (ed) Dams and reservoirs, societies and environment in the 21st century. Taylor \& Francis Group, London

51. Hrenya CM, Sinclair JL (1997) Effects of particle-phase turbulence in gas-solid flows. AIChE J 43(4):853-869

52. Jha SK, Bombardelli FA (2010) Toward two-phase flow modeling of nondilute sediment transport in open channels. J Geophys Res 115:F03015

53. Jiménez J (2004) Turbulent flows over rough walls. Annu Rev Fluid Mech 36:173-196

54. Johnson MC, Savage BM (2006) Physical and numerical comparison of flow over ogee spillway in the presence of tailwater. J Hydraul Eng ASCE 132(12):1353-1357

55. Launder BE, Spalding DB (1972) Lectures in mathematical models of turbulence. Academic Press, London

56. Matos J (2000) Hydraulic design of stepped spillways over RCC dams. In: Proceedings of the 1st international workshop on hydraulics of stepped spillway, Zurich, Switzerland. Balkema AA Publisher, Rotterdam, pp 187-194

57. Matos J, Frizell KW (1997) Air concentration measurements in highly turbulent aerated flow. In: Wang SSY, Carstens T (eds) Proceedings of the 27th IAHR congress, Theme D, vol 1, San Francisco, USA, pp 149-154

58. Matos J, Frizell KW (2000) Air concentration and velocity measurements on self-aerated flow down stepped chutes. In: Proceedings of the ASCE 2000 conference, Minneapolis, USA

59. Matos J, Sanchez-Juny M, Quintela A, Dolz J (1999) Characteristic depth and pressure profiles in skimming flow over stepped spillways. In: Proceedings of the 29th IAHR congress, Graz, Austria 
60. Matos J, Frizell KH, André S, Frizell KW (2002) On the performance of velocity measurement techniques in air-water flows. In: Proceedings of the EWRI/IAHR joint conference on hydraulic measurements \& experimental methods ASCE, Estes Park, USA

61. Matthews BW, Fletcher CAJ, Partridge AC, Vasquez S (1999) Computations of curved free surface water flow on spiral concentrators. J Hydraul Eng ASCE 125(11):1126-1139

62. Matthews BW, Fletcher CAJ, Partridge AC, Vasquez S (2001) Computations of curved free surface water flow on spiral concentrators. J Hydraul Eng ASCE 127(7):629-631

63. Meireles M (2004) Emulsionamento de Ar e Dissipação de Energia do Escoamento em Descarregadores em Degraus. M.Sc. thesis, IST, Lisbon, Portugal (in Portuguese)

64. Meireles I, Matos J (2009) Skimming flow in the non-aerated region of stepped spillways over embankment dams. J Hydraul Eng ASCE 135(8):685-689

65. Meireles I, Matos J, Melo JF (2006) Skimming flow properties upstream of air entrainment inception on steeply sloping stepped chutes. In: Proceedings of the international symposium on hydraulic structures IAHR, Ciudad Guayana, Venezuela

66. Ohtsu I, Yasuda Y (1997) Characteristics of flow conditions on stepped channels. In: Proceedings of the 27th IAHR congress, San Francisco, Theme D, pp 583-588

67. Ohtsu I, Yasuda Y, Takahashi M (2004) Flow characteristics of skimming flows in stepped channels. J Hydraul Eng ASCE 130(9):860-869

68. Paxson G, Savage B (2006) Labyrinth spillways: comparison of two popular U.S.A. design methods and consideration of non-standard approach conditions and geometries. In: Matos J, Chanson H (eds) Proceedings of the international junior researcher and engineer workshop on hydraulic structures, report CH61/06, Division of Civil Engineering, The University of Queensland, Brisbane, Australia. ISBN 1864998687

69. Pope SB (2000) Turbulent flows. Cambridge University Press, Cambridge

70. Prosperetti A, Tryggvason G (2007) Computational methods for multiphase flow. Cambridge Press, Cambridge

71. Renna F (2004) Caratterizzazione Fenomenologica del Moto di un Fluido Bifasico Lungo Scaricatori a Gradini. Ph.D. thesis, Politecnico di Bari, Cosenza, Italy (in Italian)

72. Rodi W (1984) Turbulence models and their application in hydraulics. State-of-the-Art Paper, IAHR

73. Rodríguez JF, Bombardelli FA, García MH, Frothingham K, Rhoads BL, Abad JD (2004) High-resolution numerical simulation of flow through a highly sinuous river reach. Water Resour Manag 18:177-199

74. Sánchez-Juny M (2001) Comportamiento Hidráulico de los Aliviaderos Escalonados en Presas de Hormigón Compactado. Análisis del Campo de Presiones. Ph.D. thesis, UPC, Barcelona, Spain (in Spanish)

75. Savage BM, Johnson MC (2001) Flow over ogee spillway: physical and numerical model case study. J Hydraul Eng ASCE 127(8):640-649

76. Savage B, Frizell K, Crowder J (2004) Brains versus brawn: the changing world of hydraulic model studies. In: Proceedings of the 2004 annual conference, Association of State Dam Safety Officials (ASDSO), Phoenix, USA

77. Song CCS, Zhou F (1999) Simulations of free surface flow over spillway. J Hydraul Eng ASCE 125(9):959-967

78. Storti MA, Nigro NM, Paz RR, Dalcín L (2008) Dynamic boundary condition in computational fluid dynamics. Comput Methods Appl Mech Eng 197(13-16):1219-1232

79. Tabbara M, Chatila J, Awwad R (2005) Computational simulation of flow over stepped spillways. Comput Struct 83:2215-2224

80. Unami K, Kawachi T, Babar MM, Itagaki H (1999) Two-dimensional numerical model of spillway flow. J Hydraul Eng ASCE 125(4):369-375

81. Wade RJ, Rhoads BL, Rodriguez J, Daniels M, Wilson D, Herricks EE, Bombardelli F, Garcia M, Schwartz J (2002) Integrating science and technology to support stream naturalization near Chicago, Illinois. J Am Water Resour Assoc AWRA 38(4):931-944

82. Wilcox DC (1993) Turbulence modeling for CFD. DCW Industries, La Canada

83. Yakhot V, Orszag SA (1986) Renormalization group analysis of turbulence. I. Basic theory. J Sci Comput 1(1):3-51

84. Yakhot V, Smith LM (1992) The renormalization group, the E-expansion, and the derivation of turbulence model. J Sci Comput 3: 35-61

85. Yasuda Y, Ohtsu I (2003) Effect of step cavity area on flow characteristics of skimming flows on stepped chutes. In: Proceedings of the 30th IAHR international congress, Thessaloniki, Greece, pp 703-710

86. Yasuda Y, Takahashi M, Ohtsu I (2004) Discussion on 'Volume of fluid model for turbulence numerical simulation of stepped spillway overflow,' by Chen et al. J Hydraul Eng ASCE 130(2):170

87. Ye M, Wu C, Chen Y, Zhou Q (2006) Case study of an S-shaped spillway using physical and numerical models. J Hydraul Eng ASCE 132(9):892-898 